\title{
Similarities and Differences between Child and Adult L2 Learners in the Acquisition of English Reflexives
}

\author{
Amer Al Kafri \\ Newcastle University, Newcastle upon Tyne, UK \\ Email: amer.alkafri@newcastle.ac.uk
}

How to cite this paper: Al Kafri, A. (2019). Similarities and Differences between Child and Adult L2 Learners in the Acquisition of English Reflexives. Open Journal of Modern Linguistics, 9, 508-539.

https://doi.org/10.4236/ojml.2019.96038

Received: November 8, 2019

Accepted: December 8, 2019

Published: December 11, 2019

Copyright $\odot 2019$ by author(s) and Scientific Research Publishing Inc. This work is licensed under the Creative Commons Attribution International License (CC BY 4.0).

http://creativecommons.org/licenses/by/4.0/

\section{(c) (i) Open Access}

\begin{abstract}
This paper reports on an experimental study which tested the claims of the Fundamental Difference Hypothesis and the Domain-by-Age-Model by comparing the performances of Arabic- and Chinese-speaking child and adult L2 learners in the acquisition of English reflexives. Whilst English and Arabic allow only local binding of reflexives, Chinese allows local and long-distance binding of reflexives. $60 \mathrm{~L} 2$ learners were given a word-based mean length of utterance proficiency test to confirm their proficiency level and, then, they were divided into six groups: Arabic-speaking children $(\mathrm{n}=15)$; Arabicspeaking adults $(\mathrm{n}=15)$; Chinese-speaking children $(\mathrm{n}=15)$; Chinesespeaking adults $(\mathrm{n}=15)$; an L1-English child (mean age 9.60) control group $(\mathrm{n}=15)$; and an L1-English adult control group $(\mathrm{n}=15)$. L2 learners' interpretation of English reflexives was elicited through a 48-item Simon-Saysgame. The results showed significant differences between the performance, of the L2 groups, and that of native speakers; yet, the majority of L2 learners were close to an $83.33 \%$ acquisition threshold. Also, by showing no significant difference between the child and adult L2 groups, the results indicated support for the Domain-by-Age-Model. As for the syntactic difference between reflexives and pronouns, L2 learners did not differentiate between them, scoring higher in reflexives.
\end{abstract}

\section{Keywords}

Second Language Acquisition, Reflexive Binding, Syntax, Fundamental Difference Hypothesis, Domain-by-Age Model, Universal Grammar

\section{Introduction}

For several decades, the issue, of adult L2 learners' access to Universal Grammar 
$(U G)^{1}$ has been debated. Some researchers (Schwartz \& Sprouse, 1994/1996; Eubank, 1993/1994; Vainikka \& Young-Scholten, 1994/1996; Vainikka \& YoungScholten, 2006/2007) argued that, irrespective of their L1, adult L2 learners could have access to UG in advanced stages of L2 acquisition. Others (Schachter, 1990; Bley-Vroman, 1990; Tsimpli \& Roussou, 1991; Clahsen \& Hong, 1995) argued that access to UG was confined in time and that, in their L1 to analyse L2 input, adult L2 learners resorted to insinuations of UG. In this on-going debate, two prominent hypotheses are the Fundamental Difference Hypothesis (Bley-Vroman, 1990/2009) and the Domain-by-Age-Model (Schwartz, 2003).

Bley-Vroman (1990) argues that adult L2 learners lack direct access to UG and its associated learning principles. Alternatively, adult L2 learners depend on the knowledge of their native language and general problem-solving strategies to acquire the L2 grammar. Bley-Vroman (1990) argues that there are two components which control child L1 acquisition and distinguish it from adult L2 acquisition. These are:

(1)

(a) A definition of possible grammar: Universal Grammar.

(b) A way of arriving at a grammar based on available data: a Learning Procedure (or a set of procedures).

According to Bley-Vroman, adult L2 learners, substitute UG with knowledge of the L1 and substitute domain-specific learning procedures with general-problem-solving systems.

\section{Child L2 and Adult L2 Acquisition}

Schwartz (1992) argues that, if the inter-language grammar of child and adult L2 learners is constrained by UG, there is an expectation of a single sequence of acquisition. Conversely, if a problem-solving approach guides the L2 adults' grammar, the sequence of adult L2 acquisition is expected to be different from that of child L2 acquisition. In this regard, Schwartz (2003) proposed the Domain-by-Age-Model in which she pointed out that the similarity between child L1 acquisition and child L2 acquisition lay in the realm of inflectional morphology. In contrast, the similarity, between child L2 acquisition and adult L2 acquisition, lay in the realm of syntax. This model is summarized in (2):

(2) Domain-by-Age Model (Schwartz, 2003)

(a) Child L1 $\neq$ child L2 $=$ adult L2 in the domain of syntax

(b) Child L1 $=$ child L2 $\neq$ adult L2 in the domain of inflectional morphology

Two studies (Unsworth, 2005; Blom, 2008) have been reported to test the assumptions of the Domain-by-Age Model. Unsworth (2005) investigated the acquisition of Dutch direct object scrambling over negation by child and adult English speakers. Unsworth (2005) found that L2 children and adults pass through the same developmental stages in the acquisition of scrambling. Thus, ${ }^{1}$ Universal Grammar is "a system of rules that in some explicit and well-defined way assigns structural descriptions to sentences" (Chomsky, 1965: p. 8). 
they do not scramble in stage 1 because they are still under L1 influence. Eventually, they start to scramble with increased proficiency level until they achieve native-like scrambling in stage 3. Contrary to the results of Unsworth (2005) and the assumptions of Domain-by-Age Model (Schwartz, 2003), Blom (2008) argues that age of onset affects both inflectional morphology and syntax. Blom conducted a study on Turkish and Moroccan children and adults acquiring Dutch as their second language. Blom (2008) argues that the assumptions of the Domain-by-Age Model are incorrect since adult L2 learners lag behind L2 children in both syntax and morphology. Moreover, Blom found out that L1 transfer has a marginal effect on the child participants since those child participants with short exposure to Dutch showed a good performance.

\section{Rationale of the Study}

This paper tested the claims of the Fundamental Difference Hypothesis and the Domain-by-Age Model by comparing the performances of child and adult L2 leaners in the interpretation of English reflexives. This study compares Arabicand Chinese-speaking child and adult L2 learners' acquisition of English reflexives, in particular, the differences between child and adult L2 learners in terms of their 1) acquisition of the local binding of English reflexives, 2) obedience of UG constraints on reflexives and 3) knowledge of the syntactic difference between reflexives and pronouns. As the majority of researchers concede that child L2 acquisition is enabled by UG (Schwartz, 2003), this study will test whether child and adult L2 learners whose first language is the same follow the same path of development in the acquisition of English reflexives (Domain-by-Age Model) or they follow different paths (Fundamental Difference Hypothesis). If there were no significant differences between child and adult L2 learners, who share the same mother tongue, in the acquisition of English reflexives, this would support the claims of the Domain-by-Age Model that adult L2 acquisition is still enabled by UG. However, if child L2 learners were better and there were significant differences between child and adult L2 learners in the acquisition of English reflexives, this would support the claim of the Fundamental Difference Hypothesis that adult $\mathrm{L} 2$ acquisition is not constrained by UG.

This study's theoretical background relied on UG as an approach of principles and parameters (Chomsky, 1981/1986); these were used to analyse the co-referential relationship between reflexives and their potential antecedents. In addition to Chomsky's (1981/1986) approach, a new theoretical account (Progovac, 1993) was incorporated to account for the cross-linguistic variation in reflexive binding.

\section{UG and Reflexive Binding}

A generative account of reflexive binding

Children, who acquire their native language, are endowed with UG principles (Chomsky, 1981). An example, of these principles, is the Standard Binding The- 
ory's three principles which determine the referential relationship between nominal expressions and their antecedents (Chomsky, 1986):

(3) The Standard Binding Theory (Chomsky, 1986: p. 166)

(a) An anaphor is bound in a local domain

(b) A pronominal is free in a local domain

(c) An r-expression is free (in the domain of the head of its chain)

In the light of these three principles, the referential relationship, in (4), is determined as follows:

(4)

(a) John said Jack $_{\mathrm{i}}$ likes himself $\mathrm{f}_{\mathrm{i} / \mathrm{j}_{\mathrm{j}}}$.

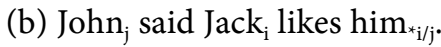

(c) $\mathrm{He}_{\mathrm{i}}$ said Jack $\mathrm{r}_{\mathrm{i}}$ is happy.

The relationship, between the above mentioned nominal expressions, is illustrated through the use of subscripted notations. As shown in (4a), the reflexive pronoun, himself, can refer to Jack because it is within the reflexive's local domain; however, it cannot refer to John, the subject of the main clause, because it is outside the local domain. In contrast, the personal pronoun, him in (4b), cannot refer to Jack, the subject of the embedded clause, because it is within the pronoun's local domain. However, him can refer to John because it is not in its local domain. As for the r-expression, Jack in (4c), it should be free and, consequently, it cannot refer to he, the subject of the main clause.

Chomsky (1981: p. 184) defined binding as:

(5) An NP, $A$, is BOUND if and only if there is an NP $B$ such that both of the following conditions are satisfied:

(a) $A$ and $B$ are co-indexed; and

(b) $B$ c-commands $A$.

Co-indexation is defined in terms of co-reference; we say that $A$ is co-indexed with $B$, if both $A$ and $B$ share the same indices; these are used commonly as notations to indicate the relationship between nominal expressions (Chomsky, 1981). C-command, however, is still a controversial topic in literature. Nevertheless, for our discussion, we adopted the definition used in Chien \& Wexler (1987: p. 30), "in a phrase-marker, node $A$ c-commands node $B$ if and only if the first branching node which dominates $A$ also dominates $B$."

Cross-linguistic variation shows that Principle $A$, in the Standard Binding Theory, cannot account for reflexive distribution in what is called long-distance binding languages, e.g. ziji in Chinese.

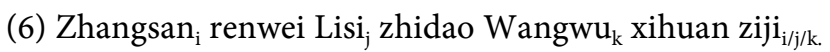

Zhangsan thinks Lisi knows Wangwu likes self.

"Zhangsan thinks that Lisi knows that Wangwu likes self"

(Progovac, 1993)

The Standard Binding Theory fails to give an account for the co-referrential relationship between ziji and its possible antecedents in (6) above. Therefore, Progovac (1993) proposed the Relativized Subject Approach to account for the 
cross-linguistic variation attested in the distribution of reflexives and their antecedents. Progovac (1993) assumed a distinction between morphologically complex reflexives (e.g. himself) and morphologically simple reflexives (e.g. ziji). Whilst complex reflexives do not take Agr as their binder, simple reflexives do. In this regard, Progovac argued that there is a close relationship between the type of $( \pm)$ Agr and the domain for simple reflexives. Namely, if a language, which allows long-distance binding, has overt morphological agreement, then, the domain, of long-distance reflexives, closes off with the first finite clause (e.g. Russian). However, if a language, which allows long-distance binding, does not have overt morphological agreement but has anaphoric Agr, the domain, of long-distance reflexives, can overlook finite clauses (e.g. Chinese). Taking these differences into account, Progovac (1993: p. 757) proposed the Relativized Subject Approach which states that:

(7) A reflexive R must be bound in the domain D containing R, a governor for $\mathrm{R}$, and a SUBJECT (see Chomsky, 1981).

(a) If $\mathrm{R}$ is an $\mathrm{X}^{\circ}$ (mono-morphemic) reflexive, then its SUBJECTs are $\mathrm{X}^{\circ}$ categories only, namely Agr (as the only salient (c-commanding) head).

(b) If $\mathrm{R}$ is an $\mathrm{X}^{\max }$ (morphologically complex) reflexive, its SUBJECTs are $\mathrm{X}^{\max }$ specifiers, therefore [NP, IP] and [NP, NP].

According to (7), the choice of a possible antecedent to any type of reflexives depends on X-bar compatibility. Progovac (1993) assumed a relationship between the morphological status of a reflexive and its SUBJECTS. Namely, if the reflexive is $\mathrm{X}^{\circ}$ (e.g., ziji), then, its SUBJECTS are only $\mathrm{X}^{\circ}$ categories. Therefore, Agr is the only c-commanding head. According to this argument, ziji, in (8), is bound by Agr in the local clause:

(8) Zhangsan ${ }_{\mathrm{i}}$ Agr $2_{\mathrm{i}}$ shuo [ Lisi $_{\mathrm{i}}$ Agr $\mathrm{l}_{\mathrm{i}}$ chang piping ziji $\mathrm{i}_{\mathrm{i}}$.

Zhangsan say Lisi often criticize self

"Zhangsan says Lisi often criticizes herself"

(Progovac, 1993: p. 758)

Progovac argues that, in (8), Agr1 is bound to Agr2 by transitivity. In this sense, Progovac explains that binding is feature-indexing and not co-reference indexing which would result in an actual co-reference as is the case in the relationship between complex reflexives and their antecedents. Since Agr is not a referential entity and it is co-indexed conventionally to its SUBJECT (Chomsky, 1981), Lisi and Zhangsan, in (8), are co-indexed by transitivity of their Agrs (Progovac, 1993).

\section{Properties of reflexives in Arabic and Chinese}

Similar to English reflexives, Arabic ${ }^{2}$ reflexives are bound locally by subject/object antecedents (Kremers, 1997).

(9) humma ${ }_{i}$ sim?-u ?inn ${ }_{\mathrm{NP}}[\text { Pahmad w mona }]_{j}$ bi-y-Hibb-u nafs-uhum * $_{\mathrm{i} /}$

${ }^{2}$ The researcher assumes that the binding grammar, of reflexives in the different dialects of Arabic, is the same as the binding grammar of reflexives in Modern Standard Arabic. This assumption is based on data which the researcher collected from speakers of different dialects of Arabic. 
they heard-3pl that Ahmad and Mona PRES-3-like-pl self-their

"they heard that Ahmad and Mona like themselves."

(Osman, 1990: p. 160)

As shown in (9), the reflexive, nafs-uhum "themselves", can be bound by the embedded subject Pahmad w mona "Ahmad and Mona"; however, it cannot be bound by humma "they" because it is outside its local domain, namely the embedded finite clause.

Similar to English, Arabic reflexives can be bound by any local c-commanding subject or object antecedents (Kremers, 1997):

(10) ḥattā ekšifa-hu ${ }_{\mathrm{i}}-1$-batal ${ }_{\mathrm{j}}$ 'amāma nafs-a-hu $\mathrm{j}_{\mathrm{j} / \mathrm{i}}$ so that reveals.3msg-him the-hero before SELF-NOM-him

"so that the hero reveals him before himself"

Different from Arabic and English, Chinese has two types of reflexives: morphologically complex (e.g., ta ziji); and morphologically simple (e.g., ziji) (Progovac, 1993). Ta ziji is a local reflexive pronoun which should be bound in its local domain, whilst ziji is a long-distance reflexive pronoun which, as shown in (11), can be bound by long-distance antecedents:

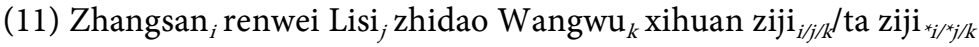

Zhangsan thinks Lisi knows Wangwu likes self he-self

"Zhangsan thinks that Lisi knows that Wangwu likes himself"

(Progovac, 1993: p. 757)

Most importantly, ziji cannot be bound by long-distance object antecedents because objects are not $\mathrm{X}^{\circ}$ categories. In fact, such a property of ziji is predicted by generative grammarians to be universal for all natural languages (Progovac, 1993). In other words, no natural language allows long-distance reflexives to be bound by long-distance object antecedents. Consequently, long-distance reflexives have only subject orientation. Table 1 below summarizes the differences in the properties of reflexives in English, Arabic and Chinese.

\section{Previous Research on the Acquisition of Reflexives}

A substantial number of studies (Finer \& Broselow, 1986; Thomas, 1989, 1995; Bennett, 1994; Maclaughlin, 1998; Yip \& Tang, 1998; Yuan, 1998; Al Kafri, 2008; among others) considered the interpretation of reflexives by adult L2 learners. These studies reported contradictory results about the adult L2 learners' interpretation of reflexives.

Table 1. Properties of reflexives in english, arabic and chinese.

\begin{tabular}{ccc}
\hline Language & Reflexive Domain & Reflexive Orientation \\
\hline English & Local & Subject/Object \\
Arabic & Local & Subject/Object \\
& Local (taziji) & Subject/Object \\
Chinese & Long-distance $(z i j i)$ & Subject \\
\hline
\end{tabular}


To start with the full access view to UG in L2 acquisition, Thomas (1995) conducted a study of 58 adult L2 learners of Japanese which allows long-distance binding of reflexives. The L2 learners were of a variety of L1s which allow local binding (English, Spanish, German and French) and long-distance binding (Thai, Chinese and Korean). Based on the results of a truth-value-judgementtask, Thomas found that advanced adult L2 learners were able to reset their binding parameter to the long-distance binding allowed in Japanese. However, Thomas's results were questionable because, in her study, she did not mention whether or not L2 learners, who achieved native-like in the acquisition of Japanese reflexives, were of an L1 which allows local or long-distance binding. Similar to Thomas's (1995) findings, Yip \& Tang (1998) conducted a study of 268 L1-Cantonese speakers adult L2 learners of English. Although Chinese allows long-distance binding of reflexives, Yip and Tang found that adult L2 learners showed gradual development and an increased proficiency level in the acquisition of local English reflexives.

In contrast to the full access view, Yuan (1998) and Al Kafri (2008) supported an L1-transfer view in the acquisition of L2 reflexives. Yuan (1998) conducted a study of L1-Japanese speakers $(\mathrm{n}=24)$ and L1-English speakers $(\mathrm{n}=57)$ acquiring Chinese as their L2. The choice of L1s and L2 was for comparative reasons because Japanese and Chinese allow long-distance binding of reflexives whilst English allows only local binding of reflexives. Using a multiple choice comprehension test, Yuan found that the Japanese participants achieved native-like acquisition of Chinese reflexives whilst the English participants were influenced by the local binding of English reflexives. Therefore, they were significantly different to the control group. Similar to Yuan's findings, Al Kafri (2008) conducted a study of L1-Arabic speakers and L1-Chinese speakers who were adult L2 learners of English. Whilst Chinese allows long-distance binding of reflexives, Arabic, similar to English, allows only local binding of reflexives. Al Kafri (2008) found that advanced L1-Arabic participants achieved native-like acquisition of English reflexives whilst the L1-Chinese speakers advanced L2 learners of English were significantly different to the English control group.

Different from the views of $\mathrm{L} 1$ transfer and L2 access to UG in adult L2 acquisition, some linguists (Finer \& Broselow, 1986; Hirakawa, 1990; Maclaughlin, 1998) conducted studies on the adult L2 learners' interpretation of English reflexives. All these studies' results showed that adult L2 learners developed a kind of grammar which was different from mother tongue binding and target binding. For example, Finer \& Broselow (1986) conducted a pilot study of six adult L1-Korean speakers' interpretation of English reflexives by. Contrary to expectations, Finer \& Broselow (1986) found that their participants developed a kind of intermediate grammar which was neither L1-like nor L2-like. Unexpectedly, the Korean participants reset their parameter to an intermediate setting between English and Korean.

Although the topic, of reflexive binding, has undergone extensive investiga- 
tion in adult L2 acquisition, it is under-researched in child L2 acquisition. According to my knowledge and as shown below, there are only two studies which compared the performance of child and adult L2 learners in the acquisition of reflexives. If that is correct, this indicates that there is a research gap which needs to be bridged in order to reach conclusive results about access to UG in adult $\mathrm{L} 2$ acquisition.

The first study was conducted by Lee \& Schachter (1997) who studied the acquisition of binding principles $A$ and B from a maturational point of view. They were interested mainly in three types of L2 learners: 1) those whose sensitive periods remained open whilst acquiring the binding principles, 2) those whose sensitive periods remained open but had not reached their peak, and 3) those who have passed the sensitive period. 76 L1-Korean speakers, acquiring English as their L2, participated in the study and 12 adult native speakers were recruited as a control group. L2 participants were divided into age groups ranged from age 6:0 to 24:11. The test was a truth-value-judgment-task where participants were shown a picture followed by a reflexive/pronoun statement. Depending on their understanding of the picture, L2 learners had to decide whether the statement was correct (choose YES) or not (choose NO). Lee and Schachter found that the performance of middle learners, particularly the 11 to 13 age group, was better than the early and later learners. Based on these results, Lee \& Schachter (1997) claimed that a sensitive period for principle A exists between the ages 5 and 13. After that age, there would be a gradual decline in the ability to acquire the local binding of English reflexives. However, the relatively low performance, of the early participants, could have resulted from the task which was used. It was highly possible that those children found the task difficult or uninteresting so their performance was lower than the middle arrivals. Lee \& Schachter (1997) ought to have used a task which took into account the difference in working memory capacity between L2 children and adults (Unsworth, 2008).

The second study was by Lee (2005) who investigated the development of the acquisition of English reflexives by adult and child L1-Korean speakers as L2 learners of English. Korean is different from English in the fact that it allows both local and long-distance binding of reflexives. Two versions of a picture truth-value-judgment task were administered to participants. Table 2 shows the participants' overall results.

As shown in Table 2, child participants, at an advanced stage, behaved native-like in type 1 and type 2 . However, their performance, in orientation ${ }^{3}$ (type 3), was more L1-like (subject only) rather than like English which accepts both subject and object antecedents. On the other hand, in type 1 sentences, adult Korean participants performed less native-like than child participants. As for L2 acquisition development, Lee (2005) found that the adult participants' results supported the Full Transfer/Full Access Model (Schwartz \& Sprouse, 1994/96).

${ }^{3}$ Orientation refers to the type of the antecedent whether it is a subject or an object. 
Table 2. Group results of accuracy from a picture-truth-value-judgment task (Lee, 2005).

\begin{tabular}{|c|c|c|c|c|c|c|c|}
\hline \multirow[b]{2}{*}{ Groups } & \multirow[b]{2}{*}{ Prof. level } & \multicolumn{2}{|c|}{$\begin{array}{c}\text { Type } 1 \\
\%\end{array}$} & \multicolumn{2}{|c|}{$\begin{array}{c}\text { Type } 2 \\
\%\end{array}$} & \multicolumn{2}{|c|}{$\begin{array}{c}\text { Type } 3 \\
\%\end{array}$} \\
\hline & & $\begin{array}{l}\text { Loc } \\
\text { (Yes) }\end{array}$ & $\begin{array}{c}\text { LD } \\
\text { (No) }\end{array}$ & $\begin{array}{c}\text { Loc } \\
\text { (Yes) }\end{array}$ & $\begin{array}{c}\text { LD } \\
\text { (No) }\end{array}$ & $\begin{array}{c}\text { Object } \\
\text { (Yes) }\end{array}$ & $\begin{array}{c}\text { Subject } \\
\text { (Yes) }\end{array}$ \\
\hline \multirow{3}{*}{ Children } & Low $(\mathrm{n}=17)$ & 63 & 48 & 66.67 & 55.67 & 37 & 77.67 \\
\hline & Intermediate $(\mathrm{n}=16)$ & 96 & 75 & 83.33 & 58.33 & 37.67 & 96 \\
\hline & High (16) & 92.67 & 81.33 & 89 & 70.33 & 33.33 & 77.67 \\
\hline \multirow{3}{*}{ Adults } & Low $(n=16)$ & 85.33 & 35.33 & 29.33 & 21 & 52 & 48 \\
\hline & Intermediate $(\mathrm{n}=17)$ & 84.33 & 45 & 47 & 13.67 & 49 & 45 \\
\hline & $\operatorname{High}(\mathrm{n}=16)$ & 81.33 & 52 & 58.33 & 33.33 & 29.33 & 68.66 \\
\hline Natives & NS $(n=6)$ & 100 & 100 & 100 & 100 & 44.33 & 89 \\
\hline
\end{tabular}

In contrast, the developmental pattern of child participants did not match that of adults. Similar to advanced adults, advanced children achieved native-like binding. However, those, who made finite/non-finite distinctions, were in the low proficiency group and not in the intermediate one. As far as orientation was concerned, no development was noticed on the part of $\mathrm{L} 2$ adults or children.

Despite the importance of Lee's (2005) study, two methodological problems could be noticed. Firstly, two totally different versions of proficiency tests were used with participants. These were a cloze proficiency test with adults and a word-based Mean Length of Utterance test with children. This meant very likely that Lee did not compare the right children with the right adults. Secondly, we do not know whether Lee's participants, especially L2 adults, allowed long-distance binding of reflexives because either they transferred the grammar of the L1, or because they misinterpreted English reflexives as pronouns. Lee included pronoun sentences in the task as distractions; however, she did not report on any results relating to the pronoun items.

As shown in the above review, the majority of L2 research, on the acquisition of reflexives, was conducted mainly on L2 adults. It is very important to conduct a study which compares the performance of child and adult L2 learners in the acquisition of reflexives. Namely, if child and adult L2 learners of the same L1 were found to follow the same path of acquisition, such findings would support the views of the Domain-by-Age-Model (Schwartz, 2003) that adults have access to UG in the acquisition of L2 syntax. However, if child L2 learners outperform adult L2 learners in the acquisitions of reflexives, such results would support the views of the Fundamental Difference Hypothesis (Bley-Vroman, 1990/2009) that adult L2 learners do not have direct access to UG and that, in the acquisition of L2 syntax, they are different from child learners.

Based on the results of the studies discussed above, this study addressed the following research questions:

(a) Will L2 learners apply UG constraints in second language acquisition?

(b) Have L2 learners reset their binding parameter to the values of the local 
binding of English reflexives?

(c) Will L2 learners differentiate between the synaptic properties of lexical items?

(d) Will there be any difference between child and adult L2 learners in the acquisition of English reflexives? (With respect to 1, 2 and 3).

\section{Experiment}

\section{Participants}

In this study, the L2 participants were from two mother tongues: Arabic and Chinese. The choice of these two languages was very important for comparative reasons. Arabic and English have the same grammar of reflexive binding in terms of domain and orientation. Chinese, in contrast, differs from English in the choice of domain and antecedents. Thus, the results of the present study will present a possible answer to the question of UG access in second language acquisition. In addition to L1-based differences between the experimental groups, there was also the age difference. This study's participants were of two age groups: children and adults. Child L2 acquisition is a subject of controversy in the field of L2 acquisition. This study adopted the definition of L2 children and L2 adults proposed by Unsworth (2005: p. 7) ${ }^{4}$ :

L2 Child: A non-native acquirer whose initial exposure, to the target language, is between the ages of four and seven years.

L2 Adult: A non-native acquirer whose initial exposure, to the target language, is at eight years or older.

The age difference within each experimental group is as important as the mother tongue difference. Since there is general consensus on the availability of UG to L2 children (Schwartz, 1992/2004; Unsworth, 2005), a comparison between child and adult participants might cast new light on the on-going debate of UG availability to adult L2 learners (Schwartz, 1992). As far as this study is concerned, similarities/differences between Arabic-speaking children and adults on one hand, and Chinese-speaking child and adult participants on the other hand, would be informative.

This study involved 90 participants who were divided into six experimental groups: Arabic-speaking children $(\mathrm{n}=15)$; Arabic-speaking adults $(\mathrm{n}=15)$; Chinese-speaking children $(\mathrm{n}=15)$; Chinese-speaking adults $(\mathrm{n}=15)$; a control group of child native speakers of English $(\mathrm{n}=15)$; and a control group of adult native speakers of English $(n=15)$. All the participants were living in the United Kingdom at the time they were tested. Table 3 presents background information on participants with regard to age and length of residence (henceforth, LOR) in the UK.

${ }^{4}$ The reason, for this choice, goes back to Unsworth's (2005) discussion which showed that the L1's most grammatical principles were in place by the age of four, and children, who started L2 acquisition before the age of eight, were found to be in the range of native-speakers. 
Table 3. Background information on participants.

\begin{tabular}{cccc}
\hline L1 & Group & $\begin{array}{c}\text { Mean Age } \\
\text { (years) }(\text { SD })\end{array}$ & $\begin{array}{c}\text { Mean Length of Residence } \\
\text { (LOR) (years) (SD) }\end{array}$ \\
\hline \multirow{2}{*}{ Arabic } & Adults $(\mathrm{n}=15)$ & $24.40(5.72)$ & $2.06(.46)$ \\
& Children $(\mathrm{n}=15)$ & $9.39(1.51)$ & $2.51(.45)$ \\
\multirow{2}{*}{ Chinese } & Adults $(\mathrm{n}=15)$ & $23.68(2.55)$ & $2.33(.48)$ \\
& Children $(\mathrm{n}=15)$ & $9.40(1.08)$ & $2.76(.41)$ \\
\multirow{2}{*}{ English } & Adults $(\mathrm{n}=15)$ & $22.75(3.46)$ & N/A \\
& Children $(\mathrm{n}=15)$ & $9.60(1.19)$ & N/A \\
\hline
\end{tabular}

An independent t-test showed that there was no significant difference between the mean ages of Arabic-speaking children; Chinese-speaking children; and English children ( $t=.177, d f(2), p>.915)$. Also, an independent t-test showed that there was no significant difference between the mean ages of Arabic-speaking adults; Chinese-speaking adults; and English adults ( $t=1.141, d f(2), p>.565)$. As for mean Length of Residence (LOR) in the UK, results of an independent t-test showed that there was no significant difference between the mean LOR for Arabic-speaking children and Chinese-speaking children $(t=1.612, d f(28)$, $p>.118$ ), and that there was no significant difference between the mean of LOR for Arabic-speaking adults and Chinese-speaking adults $(t=1.725, d f(28)$, $p>$.095).

\section{Material}

This study used two types of materials. The first one was to determine the participants' proficiency level of English, and the second was a Simon-Says game which was used to test the participants' interpretation of English reflexives.

English proficiency test. L2 learners' proficiency was determined mainly by a word-based Mean Length of Utterance (henceforth, MLU) test which was adopted from Whong-Barr \& Schwartz (2002). The test depended on an analysis of the utterances produced by $\mathrm{L} 2$ learners.

Simon-says-game. In order to investigate L2 learners' interpretation of English reflexives, the main task was a Simon-Says-Game. The game was a kind of an act-out task which involved three people: the main participant; one of his/her parents $s^{5}$ and the researcher. It involved 48 sentences which investigated sentence structures as shown in (13):

(13)

\section{(I) Biclausal Finite:}

(a) Biclausal finite reflexive

Simon says Jack $_{\mathrm{i}}$ should point to himself $\mathrm{f}_{\mathrm{i} /{ }_{\mathrm{j}}}$.

(b) Biclausal finite pronoun

Simon $_{\mathrm{j}}$ says Jack $_{\mathrm{i}}$ should point to him $_{*_{\mathrm{i} / j}}$

${ }^{5}$ When the participant was a child, one of the parents participated in the experiment. In the case of adults, one of the researcher's colleagues took over the role. 
(II) Biclausal non-finite:

(a) Biclausal non-finite reflexives

Simon $_{\mathrm{j}}$ wants Jack $_{\mathrm{i}}$ to give himself $\mathrm{i}_{\mathrm{i} / \mathrm{j}}$ a car.

(b) Biclausal non-finite pronouns

Simon $_{\mathrm{j}}$ wants Jack $_{\mathrm{i}}$ to give him ${ }_{*_{\mathrm{i} / \mathrm{j}}}$ a car.

(III) Long-distance object antecedents:

(a) Long-distance object antecedent reflexive

Simon $_{\mathrm{k}}$ tells John $\mathrm{J}_{\mathrm{j}}$ that $\mathrm{Jack}_{\mathrm{i}}$ should give himself $\mathrm{i}_{\mathrm{i} / \mathrm{j} /{ }^{*} \mathrm{k}}$ a cookie.

(b) Long-distance object antecedent pronoun

Simon $_{\mathrm{k}}$ tells John ${ }_{\mathrm{j}}$ that $\mathrm{Jack}_{\mathrm{i}}$ should give him ${ }_{*_{\mathrm{i}} / \mathrm{k} / \mathrm{k}}$ a cookie.

(IV) Possessive structures:

(a) Possessive structure 1

Simon $_{\mathrm{k}}{\text { says } \text { Sam }_{\mathrm{j}} \text { 's son }}_{\mathrm{i}}$ should give himself $\mathrm{i}_{\mathrm{i} /{ }^{*} \times \mathrm{k}}$ a ball.

(b) Possessive structure 2

Simon $_{\mathrm{k}}$ says the son $\mathrm{j}_{\mathrm{j}}$ of $\mathrm{Sam}_{\mathrm{i}}$ should give himself $_{\mathrm{*}_{\mathrm{i} / j /{ }^{*} \mathrm{k}}}$ a ball.

Participants were expected to respond according to their understanding of the game. For example, when the experimenter said a sentence such as (13, II a), if the participant had knowledge of reflexives, s/he was expected to give the car to himself/herself, not to Simon.

\section{Procedure}

The study was conducted via individual meetings with the participants. The test started with about 8 to 10 minutes recording for each participant to decide his/her proficiency level in English; each participant was shown six pictures of the Simpson Family cartoon, and the conversation concentrated on what they could tell about those pictures. Once the proficiency test finished, the SimonSays game started. Firstly, five practice sentences were tried out to avoid any misunderstandings during the game and to ensure that the participants were familiar with the test structures and what they were going to do in the game. Example (14) shows the five practice sentences used in the test.

(14)

(a) Simon says Jack should touch John.

(b) Simon wants Jack to touch John.

(c) Simon tells Jack that John should point to Simon.

(d) Simon says Sam's son should point to Simon.

(e) Simon says the son of Jack should touch Simon.

In the game, three participants (the main participant; one of his/her parents; and the researcher) needed to be present depending on the main participant's gender and to avoid gender cues in the questions. All the materials, which were required for the game such as cars, balls, and cookies, were on a table in front of the three participants. Since the game was a comprehension act-out task, the participants' responses were considered correct if they behaved correctly in the game.

Scoring and analysis

Scoring and analysis of the proficiency test 
This study adapted the definition of an utterance adopted by Whong-Barr \& Schwartz (2002: p. 610) ${ }^{6}$ who defined an utterance as "a clause with a unified predicate (unified in that it expresses a single activity, event, or state)." In this test, the complexity measure was a word-based Mean Length of Utterance (henceforth, MLU) which was calculated by dividing the total number of words by the total number of utterances. On the other hand, the accuracy measure was calculated by dividing the total number of utterances to the total number of error-free utterances. In order to make the accuracy and complexity measures comparable, the accuracy measure was multiplied by 10 . Also, the two measures were normalized by multiplying the complexity measure by the ratio of ranges which was calculated by dividing the range of accuracy measure to the range of complexity measure (Lee, 2005). Following these mathematical steps, the proficiency score was obtained by using the following formula:

(15) Proficiency Score $(\mathrm{P})=$ Accuracy Measure $+\left(\right.$ Complexity Measure ${ }^{\star}$ Ratio of ranges)

\section{Scoring and analysis of Simon-says-game}

Each participant's responses were analysed as a mean percentage for each structure type. For example, if a participant responded correctly five out of six items in biclausal finite reflexives, his/her score, in that structure type, would be 83.33\%. In this case, every participant had a mean percentage for each of the test structures.

Data was analysed into group results and individual results. Since the conditions of the task were chosen carefully to address the four research questions, data for each research question was analysed quantitatively and reported, firstly, as group results. The group results of L2 learners were analysed against the group results of control groups in order to establish if there was any significant difference between them. In addition to group results, it was important to consider the participants' individual performances to establish whether or not the participants' overall performance was indicative of their individual performances. As was the case with group results, individual results are discussed as answers to the main research questions. In order to decide whether or not L2 learners had acquired the target grammar, the main criterion, which was applied, was that each participant ought to answer correctly five items out of six in each structure type. In this discussion, the participants' identities were kept anonymous, and an acronym, plus a number, were used to refer to them as follows: AC $n$ (Arab child); AA $n$ (Arab adult); CC $n$ (Chinese child); and CA $n$ (Chinese adult).

\section{Results}

\section{Results of English proficiency test}

Proficiency data of the word-based Mean Length of Utterance test was analysed, according to the above mentioned formula, and proficiency scores ranged

${ }^{6}$ Whong-Barr \& Schwartz (2002) adapted this definition from Slobin (1993). 
between 13.7 and 16.3 (see Appendix A for proficiency results). According to a Shapiro-Wilk test, proficiency scores were found to be distributed normally $(p>.676)$ (Figure 1).

Since the proficiency scores were distributed normally, a One Way ANOVA test was applied to establish if there was any significant difference between the proficiency scores of all L2 groups. The results, of the ANOVA test, revealed that there was no significant difference between the proficiency scores of all L2 groups $(\mathrm{F}(3)=1.402, p>.252)$; this indicated that $\mathrm{L} 2$ participants were at the same developmental stage in the acquisition of English. Based on the insignificant difference found in the participants' proficiency scores, the researcher concluded that all the L2 participants, involved in this study, were at the same developmental stage in the acquisition of English. Nevertheless, the researcher did not know their specific proficiency level (elementary, intermediate or advanced).

Results of Simon-says-game

This study's results are presented as answers to each research question mentioned in (12) above. The answer, to each of these four questions, is presented, firstly, and, then, the participants' individual performances are presented. As for the group results, an acquisition threshold (83.33\%) was applied to say that L2 learners acquired any property of English reflexives. The choice of $83.33 \%$ was not arbitrary; however, it was linked to the criterion adopted in the analysis of individual results. Namely, each participant ought to have answered correctly five items out of six (83.33\%) in each structure type. According to this value/ criterion (83.33\% or 5/6), group and individual performances were analysed. Namely, any group of participants was considered to have acquired the target property of English reflexives if they satisfied the acquisition threshold and were native-like in their performances. The researcher considered the acquisition threshold to be important in the analysis of group results because, as was the case in this study, native speakers, might show, sometimes, ceiling effects whilst L2 participants do not. In such a case, we cannot claim that L2 learners have not acquired the target grammar. However, we can claim that they have acquired the target grammar but that their performances are not exactly the same as native-speakers. For this reason, the researcher applied the acquisition threshold in the analysis of group results.

\section{$U G$ constraints in the acquisition of English reflexives}

As far as UG constraints were concerned, this study argued that L2 learners obeyed UG constraints if they performed above the acquisition threshold and their performances were native-like in possessive structure 1, possessive structure 2, and long-distance object antecedent sentences. Figure 2 shows the overall performance of child experimental groups and the control group in possessive structure 1 and possessive structure 2 .

Taking the criteria of $83.33 \%$ correct performance as an acquisition threshold, Figure 2 shows that, for possessive structure 1, all the child L2 groups were performing above this threshold. However, in the acquisition of possessive structure 
2, the child L2 groups' performance was below $83.33 \%$. As expected, child native speakers showed ceiling effects in the acquisition of both possessive structures 1 and 2.

The above observations were confirmed statistically by using non-parametric tests since the data was not normally distributed. Concerning the performance of child groups, in possessive structure 1, between-group comparisons showed that there was a significant difference in possessive structures 1 (Kruskal Wallis: $\mathrm{H}(2)$ $=14.244, p<.001$ ). This was followed-up by Mann Whitney tests (Bonferroni correction applied, significance accepted at $p=.016)$ which revealed that child native speakers were significantly different from Arabic-speaking children $(U=$ 67.500, $p<.007, \mathrm{r}=.49)$ and Chinese-speaking children $(\mathrm{U}=37.500, p<.001, \mathrm{r}$ $=.69$ ).

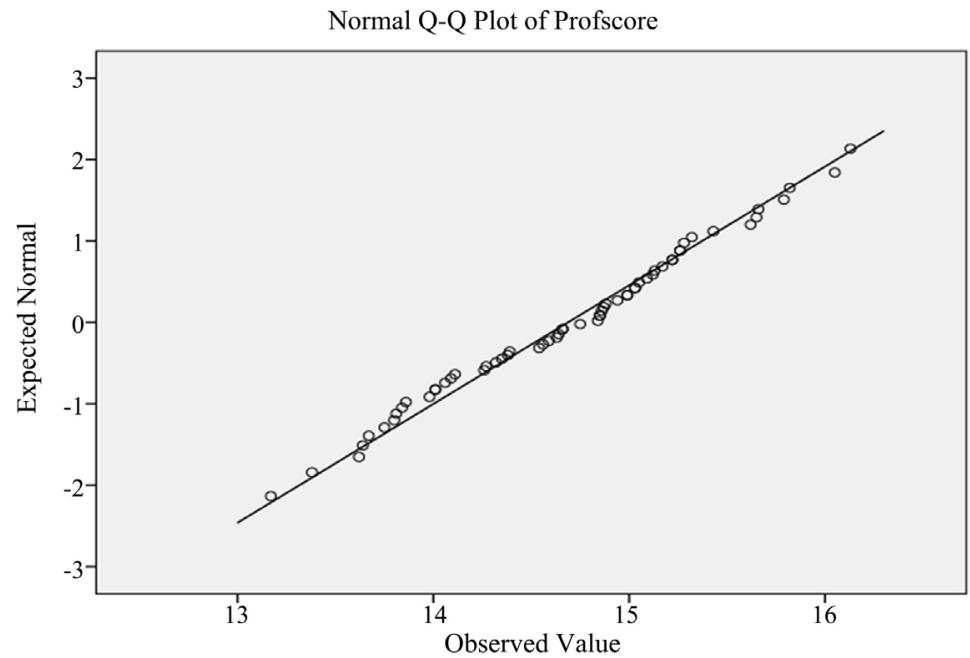

Figure 1. Normality distribution of all participants' proficiency scores.

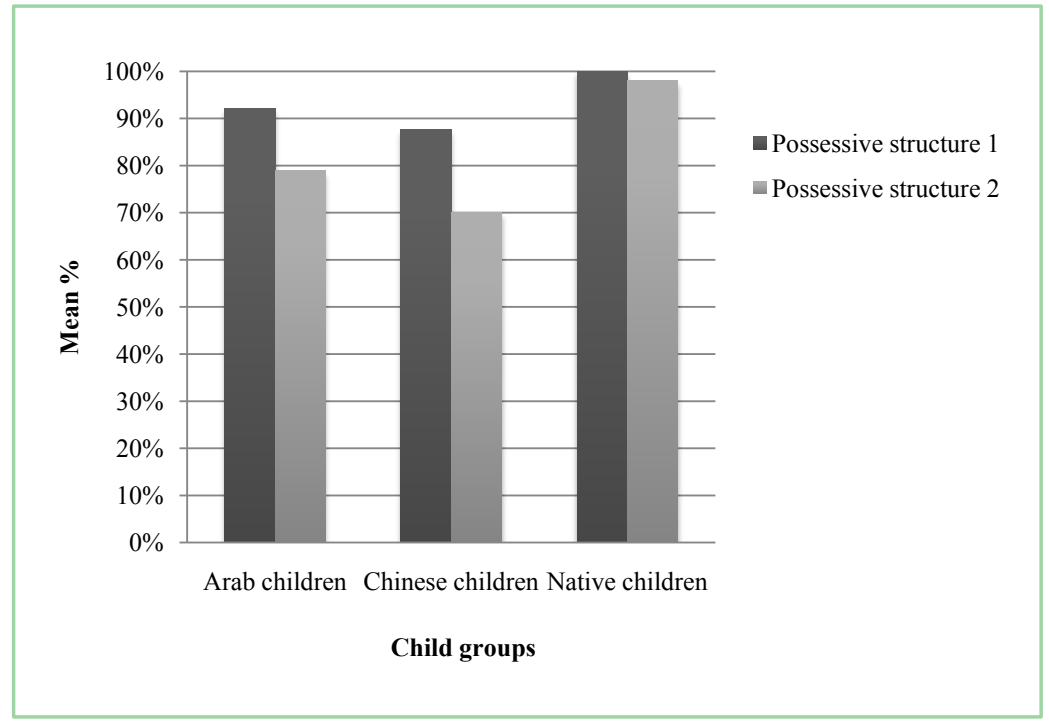

Figure 2. Correct means of child groups in possessive structure 1 and possessive structure 2. 
Concerning the performance of child groups in possessive structure 2, there were significant differences between the groups (Kruskal Wallis: $\mathrm{H}(2)=21.166$, $p<.001$ ). This was followed-up by Mann Whitney tests (Bonferroni correction applied, significance accepted at $p=.016)$ which revealed that child native speakers were significantly different from Arabic-speaking children $(U=28.00$, $p<.001, \mathrm{r}=.71)$ and Chinese-speaking children $(\mathrm{U}=23.00, p<.001, \mathrm{r}=.73)$. Now, we turn to see the performance of adult groups in possessive structure 1 and possessive structure 2 .

Similar to the child groups' results, Figure 3 shows that adult L2 groups performed above the acquisition threshold (83.33\%) for possessive structure 1 . However, their performance, in the acquisition of reflexives in possessive structure 2, was below the acquisition threshold. Similar to child native speakers in this study, adult native speakers showed ceiling effects in the acquisition of both of possessive structure 1 and possessive structure 2 .

These observations, on adults' performance, were confirmed by using nonparametric tests since the data was not normally distributed. As for possessive structure 1, there was a significant difference between the groups (Kruskal-Wallis, $\mathrm{H}(2)=11.929, p<.003$ ). This was followed up with Mann-Whitney tests (Bonferroni correction applied, significance accepted at $p=.016$ ), which revealed significant differences between native speakers and each of Arabic-speaking adults $(\mathrm{U}=60.00, p<.003, \mathrm{r}=.54)$ and Chinese-speaking adults $(\mathrm{U}=45.00, p<.001, \mathrm{r}$ $=.64)$.

Similar results were found also with the performance of adult groups in possessive structure 2 (Kruskal Wallis: $\mathrm{H}(2)=24.147, p<.001$ ). On follow-up Mann-Whitney tests (Bonferroni correction applied, significance accepted at $p$ $=.016$ ), adult native speakers were found to be significantly different from Arabic-speaking adults $(\mathrm{U}=12.00, p<.001, \mathrm{r}=.83)$ and Chinese-speaking adults ( $\mathrm{U}$ $=19.00, p<.001, \mathrm{r}=.78)$.

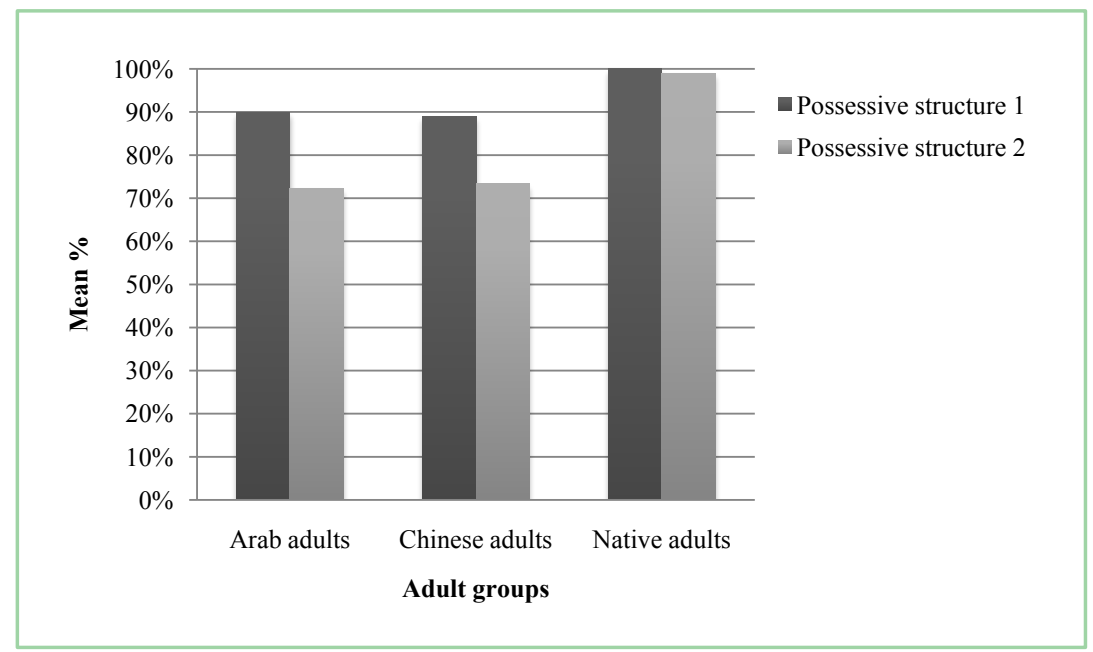

Figure 3. Correct means of adult groups in possessive structure 1 and possessive structure 2. 
In addition to their knowledge of c-command as a constraint on reflexive binding, L2 learners were shown to obey UG constraints if they did not allow English reflexives to be bound by long-distance object antecedents. Figure 4 shows the overall performance of experimental groups in prohibiting English reflexives to be bound by long-distance object antecedents.

As is obvious in Figure 4, the majority of the L2 groups scored higher than the acquisition threshold (83.33\%). Yet, on the one hand, there was a significant difference between child groups in prohibiting English reflexives to be bound by long-distance object antecedents (Kruskal Wallis, $\mathrm{H}(2)=10.278, p<.006$ ), and, on the other hand, adult groups (Kruskal Wallis, $\mathrm{H}(2)=14.521, p<.001$ ). Follow-up Mann Whitney Tests (Bonferroni correction applied, significance accepted at $p=.016$ ) showed that there was no significant difference between the performance of Arabic-speaking children and child native speakers in the interpretation of reflexives in long-distance object antecedent sentences. However, there was a significant difference between Chinese-speaking children and child native speakers $(\mathrm{U}=52.500, p<.001, \mathrm{r}=.59)$. Also, follow-up Mann Whitney Tests (Bonferroni correction applied, significance accepted at $p=.016$ ) showed that there was significant differences between the performance of adult native speakers and both Arabic-speaking adults $(\mathrm{U}=60.00, p<.003, \mathrm{r}=.54)$ and Chinese-speaking adults $(\mathrm{U}=37.500, p<.001, \mathrm{r}=.68)$.

As for the individual performance of L2 participants in respect of UG constraints in the L2 acquisition of English reflexives (see Appendix B), individual results reflected group results. Namely, the majority of Arabic-speaking children answered correctly 5/6 items in the target structures, with the exception of AC1, AC3 and AC9 whose answers were below the acquisition criterion (5/6). As for the other experimental groups, possessive structure 2 seemed to be problematic where only half of each group satisfied the acquisition criterion (5/6). Possessive structure 1 and long-distance object antecedent reflexives seemed to be less problematic for these groups. Only two Arabic-speaking participants (AC1 and AA7) and five Chinese-speaking participants (CC2, CC14, CA1, CA3 and CA7) allowed English reflexives to be bound by long-distance object antecedents.

\section{Local binding of English reflexives}

As far as the local binding of English reflexives was concerned, this study argued that L2 learners acquired the local binding of English reflexives if they performed above the acquisition threshold and their performances were native-like in both biclausal finite reflexive and biclausal non-finite reflexive sentences. Figure 5 presents the overall performance of child groups in bi-clausal finite and non-finite sentences.

As shown in Figure 5, Arabic-speaking children scored higher (83.33\%) than the acquisition threshold in biclausal finite and biclausal non-finite sentences. As for Chinese-speaking children, they scored higher than the acquisition threshold in bi-clausal non-finite sentences, and they were very close to it in bi-clausal finite sentences. As expected, child native speakers showed ceiling effects in both structures. 


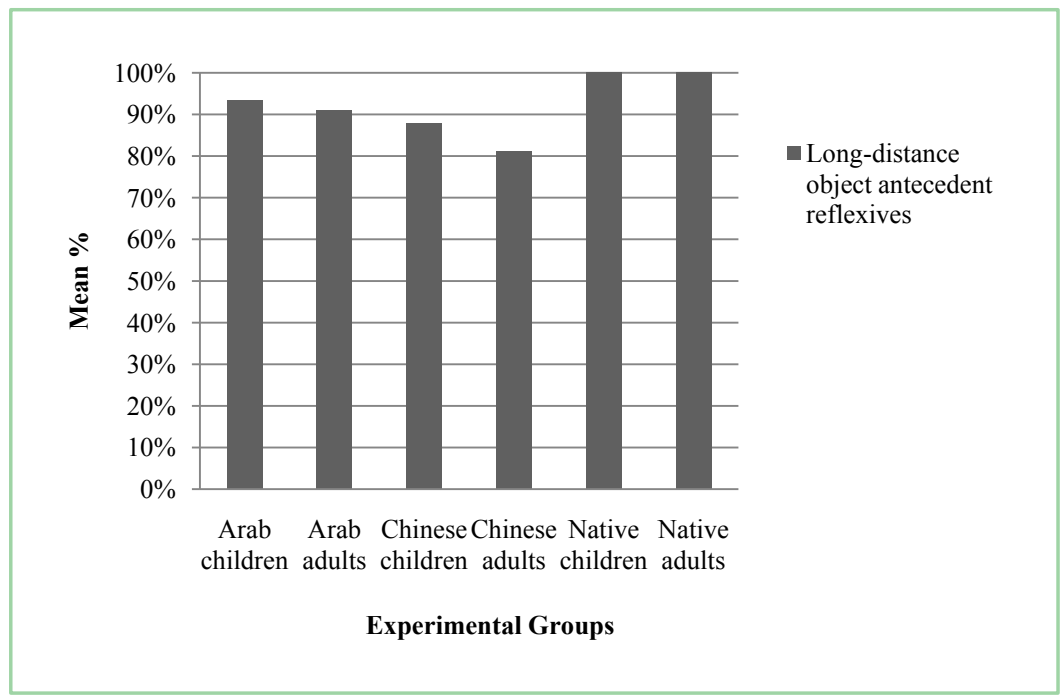

Figure 4. Correct means of participants on prohibiting English reflexives to be bound by long-distance object antecedents.

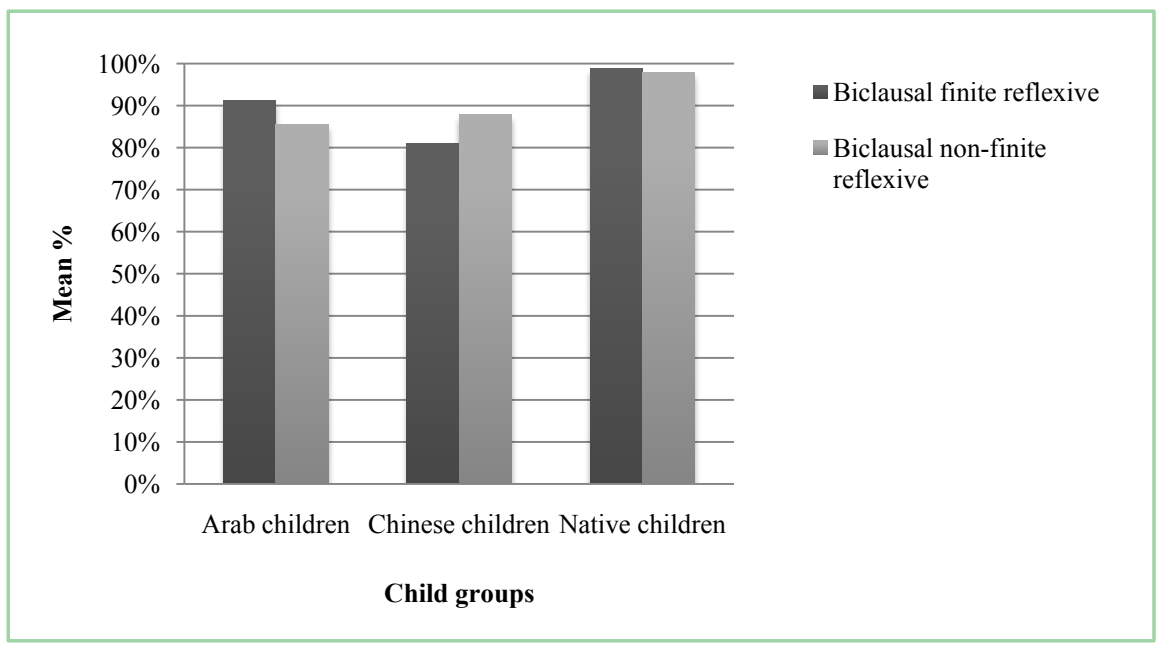

Figure 5. Correct means of child groups in biclausal finite and biclausal non-finite sentences.

However, a between-group comparison revealed that there was significant difference in biclausal finite reflexive sentences (Kruskal Wallis, $\mathrm{H}(2)=19.610, p$ $<001)$ and biclausal non-finite reflexive sentences $(\mathrm{H}(2)=12.434, p<.002)$. This was followed-up by Mann Whitney Tests (Bonferroni correction applied, significance accepted at $p=.016$ ) which showed that there was no significant difference between the performance of Arabic-speaking children and child English native speakers in biclausal finite reflexive sentences. However, on biclausal non-finite reflexive sentences $(\mathrm{U}=50.500, p<.003, \mathrm{r}=.54)$, there was a significant difference between Arabic-speaking children and child English native speakers. Conversely, there was a significant difference between the performance of Chinese-speaking children and child English native speakers in biclausal finite reflexive sentences $(\mathrm{U}=20.500, p<.001, \mathrm{r}=.77)$ and biclausal non-finite reflex- 
ive sentences $(\mathrm{U}=45.000, p<.001, \mathrm{r}=.59)$.

The native-like performance, of Arabic-speaking children in biclausal finite clauses, and the non-native-like performance, in biclausal non-finite sentences, raised the possibility of Arabic-speaking children holding a distinction between finite and non-finite clauses. To test this possibility, the performance of child groups in biclausal finite sentences was compared to their performance in biclausal non-finite sentences. A Wilcoxon Signed Ranks Test (Bonferroni correction applied, significance accepted at $p=.016)$ showed that child English native speakers, Arabic-speaking children, and Chinese-speaking children did not make a distinction between biclausal finite reflexive sentences and biclausal infinitival reflexive sentences.

Now, we turn to the results of adult groups in the acquisition of English reflexives in biclausal finite and biclausal non-finite sentences. Figure 6 shows the performance of adult groups.

As shown in Figure 6, Arabic-speaking adults scored higher than the acquisition threshold $(83.33 \%)$ in biclausal finite and biclausal non-finite sentences. In contrast, Chinese-speaking adults were somewhat below the acquisition threshold in biclausal non-finite sentences and biclausal finite sentences. Adult native speakers, as did child native speakers, showed ceiling effects in both biclausal finite and biclausal non-finite sentences.

These observations were confirmed statistically. Concerning the acquisition of reflexives in biclausal finite sentences, there was a significant difference between the groups (Kruskal-Wallis, $\mathrm{H}(2)=24.884, p<.001$ ). This was followed up with Mann-Whitney tests (Bonferroni correction applied, significance accepted at $p$ $=.016)$, which revealed that there were no significant differences between adult native speakers and Arabic-speaking adults whilst adult native speakers were significantly different to Chinese-speaking adults $(\mathrm{U}=11.00, p<.001, \mathrm{r}=.83)$.

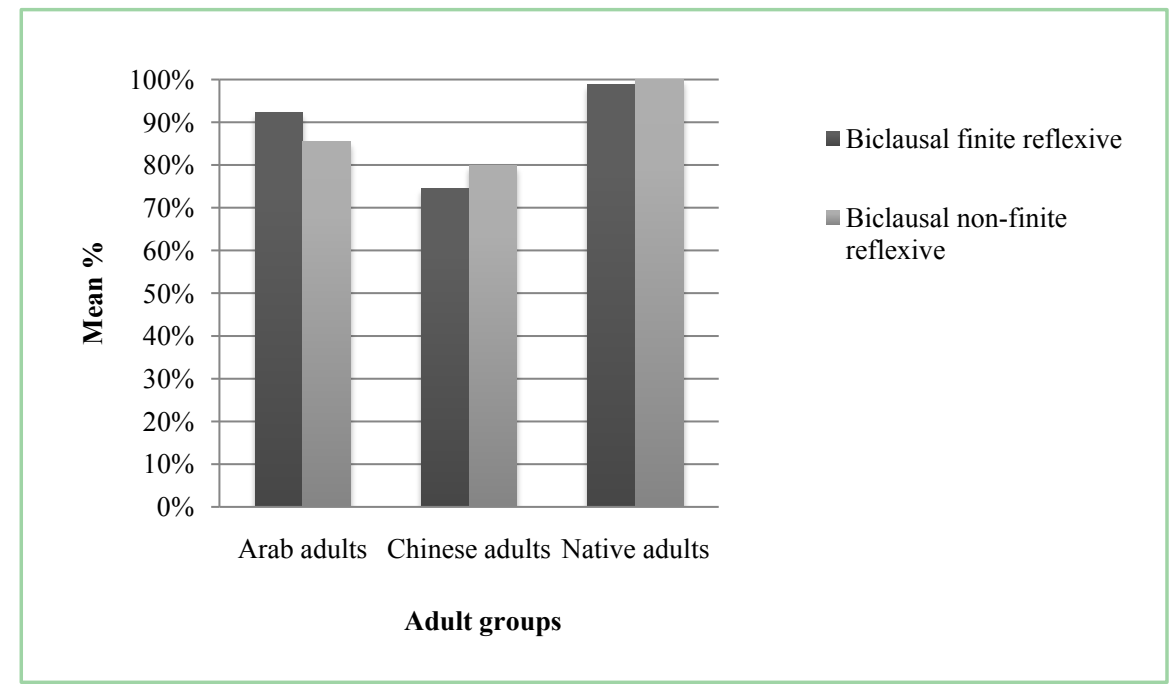

Figure 6. Correct means of adult groups on reflexives in biclausal finite and non-finite sentences. 
Concerning the acquisition of reflexives in biclausal non-finite sentences, there was a significant difference between the groups (Kruskal-Wallis, $\mathrm{H}(2)=$ 21.930, $p<.001$ ). This was followed up with Mann-Whitney tests (Bonferroni correction applied, significance accepted at $p=.016$ ), which revealed native speakers were found to be significantly different to Arabic-speaking adults $(\mathrm{U}=$ 37.500, $p<.001, \mathrm{r}=.55)$ and Chinese-speaking adults $(\mathrm{U}=15.00, p<.001, \mathrm{r}$ $=.83$ ).

If the performance of Arabic-speaking adults was native-like in biclausal finite sentences, it was not native-like in biclausal non-finite sentences. There was a possibility that they made a distinction between finite and non-finite clauses. To test such a possibility, a Wilcoxon Signed Ranks Test was used, taking into account the Bonferroni correction applied to the $p$ value $(p>.016)$. The results showed that there was no significant difference in the performance of adult English native speakers; Arabic-speaking adults; and Chinese-speaking adults with regard to the acquisition of English reflexives in biclausal finite and non-finite sentences.

As for the individual performances of L2 participants in the acquisition of local binding of English reflexives (see Appendix B), there were only three Arabic-speaking children and four Arabic-speaking adults who did not satisfy the acquisition criterion (5/6) in both finite and non-finite clauses. As for the Chinese-speaking participants, all Chinese-speaking children (with the exception of CC1, CC6, CC11, CC13 and CC15) satisfied the acquisition criterion whilst only three Chinese-speaking adults (CA1, CA12 and CA15) satisfied the acquisition criterion, and they allowed the local binding of English reflexives in biclausal finite and biclausal non-finite sentences.

\section{Syntactic difference between reflexives and pronouns}

According to the lexical learning of reflexives (Wexler \& Manzini, 1987), L2 learners learn reflexives as lexical items without considering their syntactic properties. This means that they may confuse reflexives with pronouns. Specifically, there are three possibilities: 1) constantly, L2ers misinterpret reflexives as pronouns, 2) constantly, L2ers misinterpret pronouns as reflexives, and 3) arbitrarily, L2ers confuse reflexives with pronouns without favouring one over another. Later on, children know that they are dealing with reflexives and pronouns, so they make a syntactic distinction between the two. If such a view is correct, there is a significant difference between the performance of L2ers in the acquisition of reflexives and pronouns. As shown below, Figure 7 illustrates the overall performance of experimental groups with regard to reflexives and pronouns.

Using a Wilcoxon Signed Ranks Test to compare the performance of each group with regard to reflexives and pronouns (Bonferroni correction applied, significance accepted at $p=.01$ ), the results showed that Arabic-speaking children; Arabic-speaking adults; Chinese-speaking children; Chinese-speaking adults; and English native speakers distinguished the syntactic properties of re- 
flexives and pronouns. Although the differences in the performances, of Arabic-speaking children $(\mathrm{z}=2.073, p<.038, \mathrm{r}=.53)$ and Chinese children $(\mathrm{z}=$ 2.797, $p<.05, \mathrm{r}=.72$ ), did not survive the Bonferroni correction, three was a noticeable difference in their performance. In this regard, the child participants' individual performance highlighted this difference.

As for the individual performances of L2 participants in reflexive and pronoun sentences (see Appendix B), results showed that the majority, of L2 participants and especially children, scored higher in reflexive sentences. Contrary to group results, such individual results supported the view that, at the time they were tested, the majority of L2 participants had not distinguished fully between the syntactic properties of reflexives and pronouns.

\section{Similarities/differences between child and adult L2 learners}

In addition to the comparison between the performance of native speakers and L2 groups, it was important to compare, separately, between the performance of Arabic children and adults, and the performance of Chinese children and adults. The results of such a comparison would address the question whether or not adult L2 learners had access to UG, and whether or not the earlier one acquired a second language the better. Also, it was necessary to compare between the performance of child groups and adult groups to establish whether or not L2 learners from different L1s were at the same stage of L2 acquisition. Respectively, Figure 8 and Figure 9 show the performance of Arabic-speaking groups and Chinese groups in reflexive sentences.

As shown in Figure 8, in all structures types, the performance of Arabic-speaking adults was very close to that of Arabic-speaking children, scoring higher than the acquisition threshold (83.33\%) in all structures except possessive structures 2. Similarly, Figure 9 shows the performance of Chinese-speaking adults was close to the performance of Chinese-speaking children.

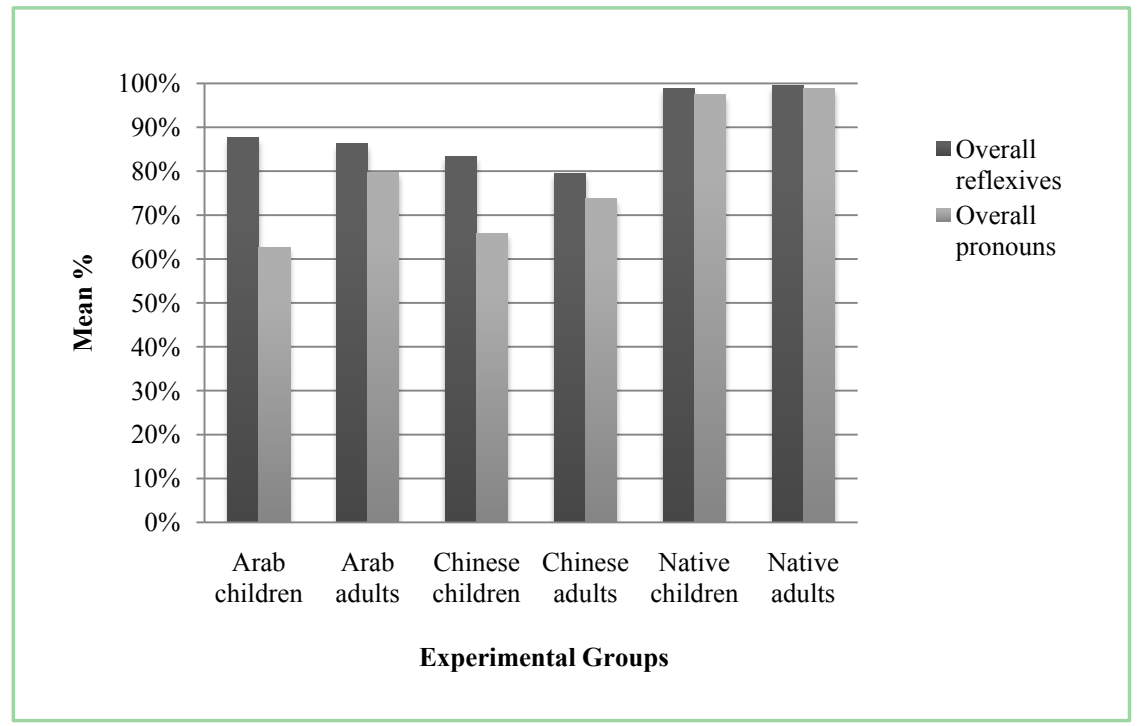

Figure 7. Correct means of experimental groups on reflexives and pronouns. 


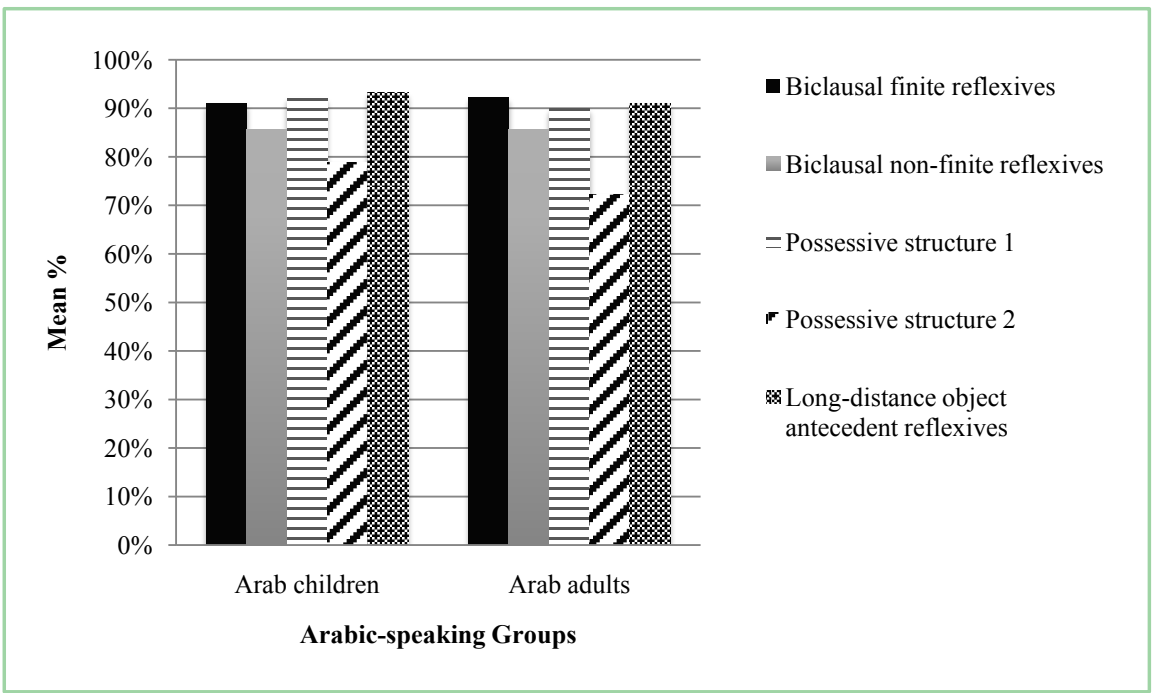

Figure 8. Correct means of Arabic-speaking groups in reflexive sentences.

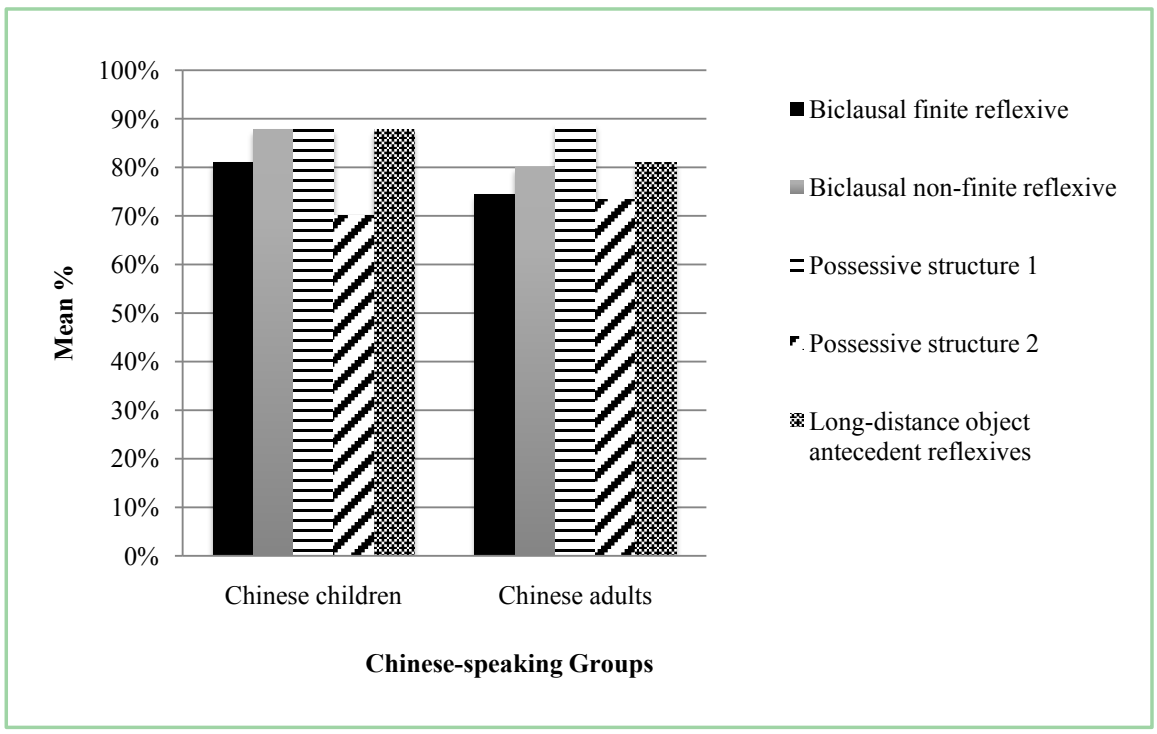

Figure 9. Correct means of Chinese-speaking groups in reflexive sentences.

Such observations were confirmed statistically. The results of between-group comparisons, using Kruskal-Wallis test, showed that there was no significant difference between the performance of L2 groups in the acquisition of English reflexives in long-distance object structures; possessive structure 1; possessive structure 2; and biclausal non-finite sentences. However, there was a significant difference in biclausal finite sentences $(\mathrm{H}(3)=19.447, p<.001)$. Follow up with Mann-Whitney tests (Bonferroni correction applied, significance accepted at $p$ $=.0125)$ revealed that there were no significant differences within the L1s, namely, on the one hand, between Arabic-speaking adults and Arabic-speaking children, and, on the other hand, Chinese-speaking adults and Chinese-speaking children. However, in the acquisition of English reflexives in biclausal finite sentences, Arabic-speaking children were significantly different to Chinese-speaking 
children $(\mathrm{U}=55.50, p<.011, \mathrm{r}=.46)$, and Arabic-speaking adults were significantly different to Chinese-speaking adults $(\mathrm{U}=35.00, p<.001, \mathrm{r}=.62)$.

\section{Discussion}

This study tested the findings of previous studies on the acquisition of reflexives and the claims of the Fundamental Difference Hypothesis (Bley-Vroman, 1989) and the Domain-by-Age-Model (Schwartz, 2003). In accordance with previous studies (Thomas, 1995; Yuan, 1998), overall results showed that L2 learners obeyed UG constraints where long-distance object antecedents were concerned. L2 learners rejected binding of English reflexives by long-distance object antecedents at a high score (above $80 \%$ ). Sometimes, as was the case with Arabic-speaking children, there was no significant difference between the performance of native speakers and that of L2 learners in prohibiting binding of reflexives by long-distance object antecedents. However, similar to the findings of Thomas (1995) and (Yuan), two-Arabic-speaking participants and five Chinese-speaking participants allowed binding of English reflexive to long-distance object antecedents but these participants' individual results showed that they misinterpreted reflexives as pronouns. Overall, the L2 participants results of prohibiting English reflexives to be bound by long-distance object antecedents indicated that, irrespective of age and mother tongue, UG was operative in the grammar of L2 learners.

The c-command constraint on reflexive binding seemed to be problematic for L2 learners. Such a view was supported by the L2 learners' individual performances. Namely, two Arabic-speaking children and about half the participants in each group of Arabic-speaking adults, Chinese-speaking children and Chinese-speaking adults could not pass the acquisition criterion in the c-command constraint. It might be possible that the c-command constraint is acquired at advanced stages of L2 acquisition. Another possibility is that, in this study, the L2 learners did not have a problem with the c-command constraint on reflexive binding, but had a problem with the lexical item itself. Namely, they misinterpreted the reflexive, himself, in (16) as a pronoun, him and, consequently, they allowed the reflexive to be bound to the non-c-commanding antecedent, Jack, whilst it should be bound by the c-commanding antecedent, The son.

(16) The son ${ }_{\mathrm{j}}$ of Jack $\mathrm{j}_{\mathrm{i}}$ pointed to himself $\mathrm{x}_{\mathrm{i} / \mathrm{j}} / \mathrm{him}_{\mathrm{i} / \mathrm{j}_{\mathrm{j}}}$.

The participants' overall results, in the reflexive/pronoun distinction, showed that they confused reflexives with pronouns. If this interpretation was correct, the participants, in this study, did not have a problem with the c-command constraint, and they did not develop a linear order learning strategy. However, at the time they were tested, they had not acquired the reflexive/pronoun distinction. Therefore, the problem would not be in the c-command constraint, but the lexical item itself.

This study's results showed also that if there was similarity between the L1 and the target grammar, the L1 influence facilitated the acquisition of the L2 target 
grammar. This conclusion is based on the evidence that there was no significant difference between the performance of native speakers and Arabic-speaking participants in the acquisition of English reflexives in biclausal finite sentences, whilst there was a significant difference between the performance of Chinesespeaking participants and that of English native speakers. Such results can be attributed to the L1 influence where there is similarity between Arabic and English in the grammar of binding and dissimilarity between English and Chinese. However, dissimilarity, between the L1 and the target grammar of L2, does not mean that L2 learners are unable to acquire the target grammar because the results showed that, in the majority of L2 structures, there was no significant difference between the performances of $\mathrm{L} 2$ learners. The only difference was in the performance of L2 learners in the acquisition of English reflexives in biclausal finite sentences, where the performance of Arabic-speaking participants was better than the performance of Chinese participants.

In the reflexive/pronoun distinction, this study showed that L2 participants, especially children, did not have full knowledge of the syntactic difference between pronouns and reflexives, and that they dealt with the majority of items as reflexives. Such an observation was obvious in the case of child participants who scored less than $70 \%$ in the majority of pronoun sentences. It might be argued that such findings contradict the claims of availability of UG principles and constraints to language learners because, if binding Principles A and B are available to language acquirers, they should be able to distinguish between reflexives and pronouns. Wexler \& Chien (1987) commented on this point by supporting a maturational account for the L1 acquisition of binding principles. They argued:

The maturational theory indicates a possible way to account for interpreting the developmental delay of Principle $B$ relative to Principle A... the three binding principles (A, B \& C) all involve the notion of linking (or non-linking) between two elements (X \& Y) in a sentence. For example, $\mathrm{X}$ can be a reflexive, pronoun or R-expression (i.e., name), and $\mathrm{Y}$ can be a potential antecedent. A principle involving disjointness between $\mathrm{X}$ and $\mathrm{Y}$ may mature later than one involving coreference.

(Wexler \& Chien, 1987: p. 39)

This study's findings support a maturational account in the L2 acquisition of reflexives and pronouns. Namely, in this study, L2 learners acquired the "notion of linking" before the notion of "non-linking."

Contrary to claims of the Fundamental Difference Hypothesis, this study's results showed that adult and child L2 learners, of the same L1 and, who were at the same proficiency level in English, were at the same developmental stage in the acquisition of English reflexives. However, since Arabic and English shared the local binding of reflexives whilst Chinese and English did not, the performance of Arabic-speaking participants was better than the performance of Chinese-speaking participants, especially adults.

This study's results support mainly the assumptions of the Domain-by-Age- 
Model in the case of Syntax (Schwartz, 2003). There was no significant difference, on the one hand, between the Arabic-speaking children's and adults' performances, and, on the other hand, there was no significant difference between the performances of Chinese-speaking children and adults. Hence, the Domain-by-Model is supported in the acquisition of L2 syntax.

\section{Conclusion}

The main aim of this study was to address the on-going debate on access to UG by adult L2ers. Different from the majority of previous studies on this topic, this study addressed the issue by comparing between the performance of adult and child L2 learners of the same L1 in the acquisition of English reflexives. The results of such a comparison, as discussed above, are very important because there is a kind of general agreement that child L2 learners still have access to UG (Schwartz, 2003/2004). Previous studies on the acquisition of reflexives by adult L2 learners have rendered contradictory views which can be summarized as follows: adult L2 learners have full direct access to UG, adult L2 learners have indirect access to UG via the L1; and adult L2 learners can a develop an intermediate binding grammar different from the L1 and L2 binding, but UG-constrained.

In accordance with previous research (Johnson and Newport, 1989; Schwartz, 2004), this study has shown that the issue of access to UG in L2 acquisition is related to UG differences rather than age differences. That is, child and adult L2 learners of the same L1 follow the same path in the acquisition of L2 syntax, while they differ in the acquisition of L2 inflectional morphology and phonology (Schwartz, 2004). Therefore, adult and child L2 learners of the same L1 showed operation of UG in the acquisition of English reflexives. Thus, the results of this study support the assumptions of the Domain-by-Age-Model (Schwartz, 2004).

Based on the results of this study, both Chinese-speaking participants and Arabic-speaking participants in developmental stages did not know the syntactic status of the item that they dealt with, so that they confused reflexives with pronouns and developed learning strategies, such as a linear order strategy. At this stage, the L1 influence will be noticed in the performance of L2 learners, so that the performance of Arabic-speaker participants will be better than the Chinese-speaking participants. However, some of the Chinese-speaking participants might overcome the L1 influence and show native-like performance in the acquisition of English reflexives. At advanced stages of L2 acquisition, L2 learners are expected to realize that they are dealing with two distinct syntactic items with different syntactic properties and a linear order strategy cannot always help them to acquire the local binding of English reflexives. Therefore, they become forced to change the values of their L1-binding parameter to that of English.

Consequently, it is a matter of differences within the language itself rather than age differences. Some aspects of language are learnable even after puberty. This implies that we can benefit from the acquisition/learning pathway of children and apply it to adults. When children learn a second language, they learn 
some aspects of language before than other aspects. This point should be further investigated in future research.

\section{Conflicts of Interest}

The author declares no conflicts of interest regarding the publication of this paper.

\section{References}

Al Kafri, A. (2008). Interpretation of English Reflexives by Non-Native Speakers (Arab and Chinese). Colchester: Essex University.

Bennett, S. (1994). Interpretation of English Reflexives by Adolescent Speakers of SerboCroatian. Second Language Research, 10, 125-156. https://doi.org/10.1177/026765839401000202

Bley-Vroman, R. (1990). The Logical Problem of Foreign Language Learning. Linguistic Analysis, 20, 3-49.

Bley-Vroman, R. (2009). The Evolving Context of the Fundamental Difference Hypothesis. Studies in Second Language Acquisition, 31, 175-198. https://doi.org/10.1017/S0272263109090275

Blom, E. (2008). Testing the Domain-by-Age Model Inflection and Placement of Dutch Verbs. In B. Haznedar, \& E. Gavruseva (Eds.), Current Trends in Child Second Language Acquisition (pp. 271-300). Amsterdam: John Benjamins. https://doi.org/10.1075/lald.46.14blo

Chien, Y.-C., \& Wexler, K. (1987). Children's Acquisition of the Locality Principle for Reflexives and Pronouns. Papers and Reports on Child Language Development, 26, 1-17.

Chomsky, N. (1965). Aspects of the Theory of Syntax. Cambridge, MA: MIT Press. https://doi.org/10.21236/AD0616323

Chomsky, N. (1981). Lectures on Government and Binding. Dordrecht: Foris.

Chomsky, N. (1986). Knowledge of Language: Its Nature, Origin, and Use. Westport, CT: Praeger.

Clahsen, H., \& Hong, U. (1995). Agreement and Null Subjects in German L2 Development: New Evidence from Reaction-Time Experiments. Second Language Research, 11, 57-87. https://doi.org/10.1177/026765839501100103

Eubank, L. (1993). On the Transfer of Parametric Values in L2 Development. Language Acquisition, 3, 183-208. https://doi.org/10.1207/s15327817la0303_1

Eubank, L. (1994). Optionality and the Initial State in L2 Development. In T. Hoekstra, \& B. Schwartz (Eds.), Language Acquisition Studies in Generative Grammar: Papers in Honor of Kenneth Wexler from the 1991 GLOW Workshops (pp. 369-388). Amsterdam: John Benjamins. https://doi.org/10.1075/lald.8.15eub

Finer, D. L., \& Broselow, E. I. (1986). Second Language Acquisition of Reflexive Binding. Proceedings of NELS, 16, 154-168.

Hirakawa, M. (1990). A Study of the L2 Acquisition of English Reflexives. Second Language Research, 6, 60-85. https://doi.org/10.1177/026765839000600103

Kremers, J. (1997). How Arabs Speak to Each Other about Themselves: A Study of NAFS and Bad in Modern Standard Arabic. Nijmegen: Katholieke Universiteit.

Lee, D., \& Schachter, J. (1997). Sensitive Period Effects in Binding Theory. Language Acquisition, 6, 333-362. https://doi.org/10.1207/s15327817la0604_3 
Lee, S. (2005). Development in the L2 Acquisition of English Reflexives by Korean Adults and Children. Honolulu, HI: University of Hawaii.

MacLaughlin, D. (1998). The Acquisition of the Morphosyntax of English Reflexives by Non-Native Speakers. In M.-L. Beck (Ed.), Morphology and Its Interfaces in Second Language Knowledge (pp. 195-226). Amsterdam: John Benjamins. https://doi.org/10.1075/lald.19.09mac

Osman, M. H. (1990). Bound Anaphora in Egyptian Arabic. In M. Eid (Ed.), Perspectives on Arabic Linguistics I (pp. 156-171). Amsterdam: John Benjamins. https://doi.org/10.1075/cilt.63.09osm

Progovac, L. (1993). Long-Distance Reflexives: Movement-to-INFL versus Relativized Subject. Linguistic Inquiry, 24, 755-772.

Schachter, J. (1990). On the Issue of Completeness in Second Language Acquisition. Second Language Research, 6, 93-124. https://doi.org/10.1177/026765839000600201

Schwartz, B. (2003). Child L2 Acquisition: Paving the Way. In Proceedings of the 27th Annual Boston University Conference on Language Development (Vol. 1, pp. 26-50).

Schwartz, B. (2004). Why Child L2 Acquisition? In J. V. Kampen, \& S. Baauw (Eds.), Proceedings of GALA 2003 (pp. 47-66). Utrecht: Graduate School of Linguistics (LOT).

Schwartz, B. D. (1992). Testing between UG-Based and Problem-Solving Models of L2A: Developmental Sequence Data. Language Acquisition, 2, 1-19.

https://doi.org/10.1207/s15327817la0201_1

Schwartz, B., \& Sprouse, R. (1996). L2 Cognitive States and the Full Transfer/Full Access Model. Second Language Research, 12, 40-72. https://doi.org/10.1177/026765839601200103

Schwartz, B., \& Sprouse, R. A. (1994). Word Order and Nominative Case in Non-Native Language Acquisition: A Longitudinal Study of (L1 Turkish). German Interlanguage. In T. Hoekstra, \& B. Schwartz (Eds.), Language Acquisition Studies in Generative Grammar: Papersin Honor of Kenneth Wexler from the 1991 GLOW Workshops (pp. 317-368). Philadelphia, PA: John Benjamins. https://doi.org/10.1075/lald.8.14sch

Slobin, D. (1993). Coding Child Language Data for Cross-Linguistic Analysis. In J. Edwards, \& M. Lampert (Eds.), Talking Data: Transcription and Coding in Discourse Research (pp. 207-219). Hillsdale, NJ: Lawrence Erlbaum.

Thomas, M. (1989). The Interpretation of English Reflexive Pronouns by Non-Native Speakers. Studies in Second Language Acquisition, 11, 281-303. https://doi.org/10.1017/S0272263100008147

Thomas, M. (1995). Acquisition of the Japanese Reflexive Zibun and Movement of Anaphors in Logical Form. Second Language Research, 11, 206-234.

https://doi.org/10.1177/026765839501100302

Tsimpli, I., \& Roussou, A. (1991). Parameter Resetting in L2 (pp. 149-169). UCL Working Papers in Linguistics.

Unsworth, S. (2005). Child L2, Adult L2, Child L1: Differences and Similarities. A Study on the Acquisition of Direct Object Scrambling in Dutch. Utrecht: Universiteit Utrecht.

Vainikka, A., \& Young-Scholten, M. (1994). Direct Access to X-Bar Theory: Evidence from Korean and Turkish Adults Learning German. In T. Hoekstra, \& B. Schwartz (Eds.), Language Acquisition Studies in Generative Grammar: Papers in Honor of Kenneth Wexler from the 1991 GLOW Workshops (pp. 265-316). Amsterdam: John Benjamins. https://doi.org/10.1075/lald.8.13vai

Vainikka, A., \& Young-Scholten, M. (1996). Gradual Development of L2 Phrase Structure. Second Language Research, 12, 7-39. 
https://doi.org/10.1177/026765839601200102

Vainikka, A., \& Young-Scholten, M. (2006). The Roots of Syntax and How They Grow: Organic Grammar, the Basic Variety and Processability Theory. In S. Unsworth, T. Parodi, A. Sorace, \& M. Young-Schoten (Eds.), Paths of Development in L1 and L2 Acquisition: In Honor of Bonnie D. Schwartz (pp. 77-106). Amsterdam: John Benjamins. https://doi.org/10.1075/lald.39.05vai

Vainikka, A., \& Young-Scholten, M. (2007). Minimalism vs. Organic Syntax. In S. Karimi, V. Samiian, \& W. K. Wilkins (Eds.), Clausal and Phrasal Architecture: Syntactic Derivation and Interpretation (pp. 319-338). Amsterdam: John Benjamins. https://doi.org/10.1075/la.101.16vai

Wexler, K., \& Manzini, R. (1987). Parameters and Learn Ability in Binding Theory. In T. Roeper, \& E. Williams (Eds.), Parameter Setting (pp. 41-76). Dordrecht: Reidel D. https://doi.org/10.1007/978-94-009-3727-7_3

Whong-Barr, M., \& Schwartz, B. D. (2002). Morphological and Syntactic Transfer in Child L2 Acquisition of the English Dative Alternation. Studies in Second Language Acquisition, 24, 579-616. https://doi.org/10.1017/S0272263102004035

Yip, V., \& Tang, J. (1998). Acquisition of English Reflexive Binding by Cantonese Learners: Testing the Positive Transfer Hypothesis. In M.-L. Beck (Ed.), Morphology and Its Interfaces in Second Language Knowledge (pp. 165-193). Amsterdam: John Benjamins. https://doi.org/10.1075/lald.19.08yip

Yuan, B. (1998). Interpretation of Binding and Orientation of the Chinese Reflexive "Ziji" by English and Japanese Speakers. Second Language Research, 14, 324-341.

https://doi.org/10.1191/026765898670904111 


\section{Appendices}

\section{Appendix A: Proficiency Scores of L2 Participants}

Table A1. Proficiency scores for Arabic-speaking adults.

\begin{tabular}{|c|c|c|c|c|c|c|c|c|}
\hline Participant & $\begin{array}{c}\text { Total } \\
\text { of } \\
\text { words } \\
\text { (A) }\end{array}$ & $\begin{array}{c}\begin{array}{c}\text { Total } \\
\text { of }\end{array} \\
\text { utterances } \\
\text { (B) }\end{array}$ & $\begin{array}{c}\text { Total of } \\
\text { error-free } \\
\text { Utterances } \\
\text { (C) }\end{array}$ & $\begin{array}{c}\text { Complexity } \\
\text { measure } \\
(D)=A / B\end{array}$ & $\begin{array}{c}\text { Accuracy } \\
\% \\
(E)=C / B\end{array}$ & $\begin{array}{c}\text { Accuracy } \\
\text { Measure } \\
(\mathrm{F})=\mathrm{Ex} 10\end{array}$ & $\begin{array}{l}\text { Prof. } \\
\text { score }\end{array}$ & $\begin{array}{c}\mathrm{T} \\
\text { score }\end{array}$ \\
\hline AA1 & 402 & 55 & 30 & 7.31 & 54.55 & 5.45 & 13.62 & 30.97 \\
\hline AA2 & 441 & 53 & 27 & 8.32 & 50.94 & 5.09 & 14.39 & 42.74 \\
\hline $\mathrm{AA} 3$ & 541 & 64 & 37 & 8.45 & 57.81 & 5.78 & 15.22 & 60.89 \\
\hline AA4 & 422 & 54 & 32 & 7.81 & 59.26 & 5.93 & 14.66 & 51.60 \\
\hline AA5 & 494 & 57 & 34 & 8.67 & 59.65 & 5.96 & 15.65 & 69.25 \\
\hline AA6 & 398 & 45 & 23 & 8.84 & 51.11 & 5.11 & 14.99 & 53.43 \\
\hline AA7 & 492 & 57 & 37 & 8.63 & 64.91 & 6.49 & 16.13 & 80.47 \\
\hline AA8 & 387 & 44 & 24 & 8.80 & 54.55 & 5.45 & 15.28 & 60.24 \\
\hline AA9 & 515 & 61 & 39 & 8.44 & 63.93 & 6.39 & 15.82 & 74.54 \\
\hline AA10 & 421 & 47 & 25 & 8.96 & 53.19 & 5.32 & 15.32 & 60.36 \\
\hline AA11 & 390 & 44 & 23 & 8.86 & 52.27 & 5.23 & 15.13 & 56.43 \\
\hline AA12 & 439 & 53 & 27 & 8.28 & 50.94 & 5.09 & 14.35 & 41.99 \\
\hline AA13 & 459 & 52 & 26 & 8.83 & 50.00 & 5.00 & 14.86 & 50.57 \\
\hline AA14 & 435 & 55 & 29 & 7.91 & 52.73 & 5.27 & 14.11 & 38.67 \\
\hline AA15 & 420 & 55 & 30 & 7.64 & 54.55 & 5.45 & 13.98 & 37.41 \\
\hline
\end{tabular}

Table A2. Proficiency scores for Arabic-speaking children.

\begin{tabular}{|c|c|c|c|c|c|c|c|c|}
\hline Participant & $\begin{array}{l}\text { Total } \\
\text { of } \\
\text { words } \\
\text { (A) }\end{array}$ & $\begin{array}{c}\begin{array}{c}\text { Total } \\
\text { of }\end{array} \\
\text { utterances } \\
\text { (B) }\end{array}$ & $\begin{array}{c}\text { Total of } \\
\text { error-free } \\
\text { Utterances } \\
\text { (C) }\end{array}$ & $\begin{array}{c}\text { Complexity } \\
\text { measure } \\
\text { (D) }=\mathrm{A} / \mathrm{B}\end{array}$ & $\begin{array}{c}\text { Accuracy } \\
\% \\
(E)=C / B\end{array}$ & $\begin{array}{l}\text { Accuracy } \\
\text { Measure } \\
\text { (F) = Ex10 }\end{array}$ & $\begin{array}{l}\text { Prof. } \\
\text { score }\end{array}$ & $\begin{array}{c}\mathrm{T} \\
\text { score }\end{array}$ \\
\hline $\mathrm{AC} 1$ & 391 & 54 & 30 & 7.24 & 55.56 & 5.56 & 13.64 & 31.91 \\
\hline AC2 & 450 & 55 & 38 & 8.18 & 69.09 & 6.91 & 16.05 & 81.08 \\
\hline $\mathrm{AC} 3$ & 477 & 54 & 32 & 8.83 & 59.26 & 5.93 & 15.79 & 71.65 \\
\hline AC4 & 402 & 56 & 34 & 7.18 & 60.71 & 6.07 & 14.09 & 42.36 \\
\hline AC5 & 488 & 58 & 35 & 8.41 & 60.34 & 6.03 & 15.43 & 65.85 \\
\hline AC6 & 397 & 48 & 26 & 8.27 & 54.17 & 5.42 & 14.66 & 49.04 \\
\hline AC7 & 483 & 55 & 30 & 8.78 & 54.55 & 5.45 & 15.26 & 59.97 \\
\hline AC8 & 503 & 62 & 37 & 8.11 & 59.68 & 5.97 & 15.03 & 58.41 \\
\hline AC9 & 400 & 50 & 28 & 8.00 & 56.00 & 5.60 & 14.54 & 47.87 \\
\hline $\mathrm{AC} 10$ & 399 & 55 & 29 & 7.25 & 52.72 & 5.27 & 13.38 & 25.78 \\
\hline AC11 & 423 & 53 & 27 & 7.98 & 50.94 & 5.09 & 14.01 & 36.05 \\
\hline $\mathrm{AC} 12$ & 492 & 56 & 30 & 8.79 & 53.57 & 5.36 & 15.17 & 57.84 \\
\hline $\mathrm{AC} 13$ & 408 & 53 & 30 & 7.70 & 56.60 & 5.66 & 14.26 & 43.29 \\
\hline $\mathrm{AC} 14$ & 456 & 52 & 27 & 8.77 & 51.92 & 5.19 & 14.99 & 53.78 \\
\hline $\mathrm{AC} 15$ & 477 & 56 & 30 & 8.52 & 53.57 & 5.36 & 14.87 & 52.57 \\
\hline
\end{tabular}


Table A3. Proficiency scores for Chinese-speaking adults.

\begin{tabular}{|c|c|c|c|c|c|c|c|c|}
\hline Participant & $\begin{array}{l}\text { Total } \\
\text { of } \\
\text { words } \\
\text { (A) }\end{array}$ & $\begin{array}{c}\text { Total } \\
\text { of } \\
\text { utterances } \\
\text { (B) }\end{array}$ & $\begin{array}{c}\text { Total of } \\
\text { error-free } \\
\text { Utterances } \\
\text { (C) }\end{array}$ & $\begin{array}{c}\text { Complexity } \\
\text { measure } \\
(D)=A / B\end{array}$ & $\begin{array}{c}\text { Accuracy } \\
\% \\
(E)=C / B\end{array}$ & $\begin{array}{l}\text { Accuracy } \\
\text { Measure } \\
\text { (F) = Ex10 }\end{array}$ & $\begin{array}{l}\text { Prof. } \\
\text { score }\end{array}$ & $\begin{array}{c}\mathrm{T} \\
\text { score }\end{array}$ \\
\hline CA1 & 403 & 48 & 24 & 8.40 & 50.00 & 5.00 & 14.38 & 42.08 \\
\hline $\mathrm{CA} 2$ & 456 & 55 & 35 & 8.29 & 63.64 & 6.36 & 15.62 & 70.88 \\
\hline $\mathrm{CA} 3$ & 471 & 57 & 29 & 8.26 & 50.88 & 5.09 & 14.32 & 41.45 \\
\hline CA4 & 389 & 55 & 29 & 7.07 & 52.73 & 5.27 & 13.17 & 22.20 \\
\hline CA5 & 455 & 55 & 31 & 8.27 & 56.36 & 5.64 & 14.88 & 54.06 \\
\hline CA6 & 423 & 53 & 27 & 7.98 & 50.94 & 5.09 & 14.01 & 36.05 \\
\hline CA7 & 477 & 54 & 28 & 8.83 & 51.85 & 5.19 & 15.05 & 54.88 \\
\hline CA8 & 467 & 54 & 30 & 8.65 & 55.56 & 5.56 & 15.22 & 59.62 \\
\hline CA9 & 439 & 60 & 34 & 7.32 & 56.67 & 5.67 & 13.84 & 35.92 \\
\hline CA10 & 485 & 55 & 28 & 8.82 & 50.91 & 5.09 & 14.94 & 52.45 \\
\hline CA11 & 431 & 53 & 29 & 8.13 & 54.72 & 5.47 & 14.56 & 47.56 \\
\hline CA12 & 449 & 54 & 30 & 8.31 & 55.56 & 5.56 & 14.84 & 53.06 \\
\hline CA13 & 458 & 56 & 32 & 8.18 & 57.14 & 5.71 & 14.85 & 53.97 \\
\hline CA14 & 503 & 57 & 30 & 8.82 & 52.63 & 5.26 & 15.12 & 56.48 \\
\hline CA15 & 463 & 56 & 36 & 8.27 & 64.29 & 6.43 & 15.66 & 71.89 \\
\hline
\end{tabular}

Table A4. Proficiency scores for Chinese-speaking children.

\begin{tabular}{cccccccccc}
\hline Participant & $\begin{array}{c}\text { Total } \\
\text { of } \\
\text { words } \\
\text { (A) }\end{array}$ & $\begin{array}{c}\text { Total } \\
\text { of } \\
\text { utterances } \\
\text { (B) }\end{array}$ & $\begin{array}{c}\text { Total of } \\
\text { error-free }\end{array}$ & $\begin{array}{c}\text { Utterances } \\
(\text { C) }\end{array}$ & $\begin{array}{c}\text { Complexity } \\
\text { measure }\end{array}$ & $\begin{array}{c}\text { Accuracy } \\
\text { (D) }\end{array}$ & $\begin{array}{c}\text { Accuracy } \\
\text { Measure }\end{array}$ & $\begin{array}{c}\text { Prof. } \\
\text { score }\end{array}$ & score \\
CC1 & 422 & 52 & 26 & 8.12 & 50.00 & 5.00 & 14.06 & 36.56 \\
CC2 & 476 & 54 & 28 & 8.81 & 51.85 & 5.19 & 15.03 & 54.52 \\
CC3 & 398 & 53 & 29 & 7.51 & 54.72 & 5.47 & 13.86 & 35.30 \\
CC4 & 443 & 55 & 31 & 8.05 & 56.36 & 5.64 & 14.63 & 49.76 \\
CC5 & 423 & 54 & 27 & 7.83 & 50.00 & 5.00 & 13.75 & 31.00 \\
CC6 & 463 & 53 & 27 & 8.74 & 50.94 & 5.09 & 14.85 & 50.91 \\
CC7 & 502 & 61 & 36 & 8.23 & 59.02 & 5.90 & 15.09 & 59.21 \\
CC8 & 409 & 52 & 31 & 7.87 & 59.62 & 5.96 & 14.75 & 53.40 \\
CC9 & 453 & 53 & 27 & 8.55 & 50.94 & 5.09 & 14.64 & 47.19 \\
CC10 & 467 & 57 & 31 & 8.19 & 54.39 & 5.44 & 14.59 & 48.01 \\
CC11 & 389 & 53 & 29 & 7.34 & 54.72 & 5.47 & 13.67 & 31.96 \\
CC12 & 422 & 53 & 26 & 7.96 & 49.06 & 4.91 & 13.80 & 31.41 \\
CC13 & 419 & 52 & 25 & 8.06 & 48.08 & 4.81 & 13.81 & 31.07 \\
CC14 & 455 & 51 & 27 & 8.92 & 52.94 & 5.29 & 15.26 & 59.09 \\
CC15 & 439 & 54 & 28 & 8.13 & 51.85 & 5.19 & 14.27 & 41.03 \\
\hline & & & & & & & & \\
\hline
\end{tabular}




\section{Appendix B: Raw Results of L2 Participants}

Table B1. Results of Arabic-speaking children.

\begin{tabular}{|c|c|c|c|c|c|c|c|c|}
\hline Participant & $\begin{array}{c}\text { BFR } \\
\%\end{array}$ & $\begin{array}{c}\text { BNR } \\
\%\end{array}$ & $\begin{array}{c}\text { LDOAR } \\
\%\end{array}$ & $\begin{array}{c}\text { PS1 } \\
\%\end{array}$ & $\begin{array}{c}\text { PS2 } \\
\%\end{array}$ & $\begin{array}{c}\text { BFP } \\
\%\end{array}$ & $\begin{array}{c}\text { BNP } \\
\%\end{array}$ & $\begin{array}{c}\text { LDOAP } \\
\%\end{array}$ \\
\hline $\mathrm{ACl}$ & 83.33 & 100 & 66.66 & 83.33 & 66.66 & 83.33 & 66.66 & 100 \\
\hline $\mathrm{AC} 2$ & 100 & 50.00 & 83.33 & 100 & 83.33 & 83.33 & 100 & 66.66 \\
\hline AC3 & 100 & 100 & 100 & 100 & 0 & 83.33 & 66.66 & 83.33 \\
\hline $\mathrm{AC} 4$ & 83.33 & 83.33 & 100 & 83.33 & 83.33 & 0 & 66.66 & 83.33 \\
\hline AC5 & 100 & 100 & 100 & 100 & 83.33 & 100 & 83.33 & 83.33 \\
\hline AC6 & 83.33 & 66.66 & 83.33 & 100 & 83.33 & 100 & 83.33 & 83.33 \\
\hline $\mathrm{AC7}$ & 100 & 83.33 & 100 & 100 & 83.33 & 16.66 & 33.33 & 0 \\
\hline $\mathrm{AC} 8$ & 100 & 83.33 & 83.33 & 83.33 & 100 & 83.33 & 66.66 & 83.33 \\
\hline AC9 & 66.66 & 83.33 & 83.33 & 66.66 & 83.33 & 66.66 & 83.33 & 100 \\
\hline $\mathrm{AC} 10$ & 83.33 & 83.33 & 100 & 83.33 & 83.33 & 66.66 & 100 & 83.33 \\
\hline $\mathrm{AC} 11$ & 100 & 83.33 & 100 & 83.33 & 83.33 & 100 & 83.33 & 83.33 \\
\hline $\mathrm{AC} 12$ & 100 & 100 & 100 & 100 & 83.33 & 16.66 & 66.66 & 83.33 \\
\hline $\mathrm{AC} 13$ & 83.33 & 83.33 & 100 & 100 & 100 & 16.66 & 16.66 & 0 \\
\hline $\mathrm{AC} 14$ & 100 & 83.33 & 100 & 100 & 83.33 & 33.33 & 16.66 & 0 \\
\hline $\mathrm{AC} 15$ & 83.33 & 100 & 100 & 100 & 83.33 & 50.00 & 33.33 & 16.66 \\
\hline
\end{tabular}

$\mathrm{BFR}=$ biclausal finite reflexives, $\mathrm{BNR}=$ biclausal non-finite reflexives, PS1 = possessive structures $1, \mathrm{PS} 2=$ possessive structures 2 , LDOAR = long-distance object antecedent reflexive, $\mathrm{BFP}=$ biclausal finite pronoun, $\mathrm{BNP}=$ biclausal non-finite pronoun, LDOAP = long-distance object antecedent pronoun.

Table B2. Results of Arabic-speaking Adults.

\begin{tabular}{ccccccccc}
\hline Participant & $\begin{array}{c}\text { BFR } \\
\%\end{array}$ & $\begin{array}{c}\text { BNR } \\
\%\end{array}$ & $\begin{array}{c}\text { LDOAR } \\
\%\end{array}$ & $\begin{array}{c}\text { PS1 } \\
\%\end{array}$ & $\begin{array}{c}\text { PS2 } \\
\%\end{array}$ & $\begin{array}{c}\text { BFP } \\
\%\end{array}$ & $\begin{array}{c}\text { BNP } \\
\%\end{array}$ & $\begin{array}{c}\text { LDOAP } \\
\%\end{array}$ \\
\hline AA1 & 100 & 100 & 100 & 100 & 0 & 83.33 & 66.66 & 100 \\
AA2 & 100 & 83.33 & 100 & 83.33 & 83.33 & 83.33 & 66.66 & 100 \\
AA3 & 100 & 83.33 & 100 & 66.66 & 83.33 & 100 & 83.33 & 83.33 \\
AA4 & 66.66 & 100 & 100 & 100 & 83.33 & 100 & 100 & 100 \\
AA5 & 100 & 83.33 & 83.33 & 100 & 66.66 & 83.33 & 100 & 100 \\
AA6 & 83.33 & 66.66 & 83.33 & 100 & 50.00 & 83.33 & 66.66 & 83.33 \\
AA7 & 83.33 & 66.66 & 66.66 & 83.33 & 83.33 & 83.33 & 66.66 & 66.66 \\
AA8 & 83.33 & 83.33 & 100 & 100 & 83.33 & 83.33 & 83.33 & 66.66 \\
AA9 & 100 & 83.33 & 100 & 83.33 & 66.66 & 83.33 & 83.33 & 66.66 \\
AA10 & 83.33 & 66.66 & 83.33 & 66.66 & 66.66 & 83.33 & 50.00 & 66.66 \\
AA11 & 100 & 100 & 100 & 100 & 100 & 50.00 & 66.66 & 16.66 \\
AA12 & 100 & 83.33 & 100 & 83.33 & 83.33 & 83.33 & 83.33 & 100 \\
AA13 & 100 & 83.33 & 83.33 & 100 & 83.33 & 100 & 83.33 & 100 \\
AA14 & 100 & 100 & 83.33 & 100 & 83.33 & 66.66 & 83.33 & 100 \\
AA15 & 83.33 & 100 & 83.33 & 83.33 & 66.66 & 83.33 & 66.66 & 83.33 \\
\hline
\end{tabular}

$\mathrm{BFR}=$ biclausal finite reflexives, $\mathrm{BNR}=$ biclausal non-finite reflexives, PS1 = possessive structures $1, \mathrm{PS} 2=$ possessive structures $2, \mathrm{LDOAR}=$ long-distance object antecedent reflexive, $\mathrm{BFP}=$ biclausal finite pronoun, $\mathrm{BNP}=$ biclausal non-finite pronoun, LDOAP = long-distance object antecedent pronoun. 
Table B3. Results of Chinese-speaking children.

\begin{tabular}{ccccccccc}
\hline Participant & $\begin{array}{c}\text { BFR } \\
\%\end{array}$ & $\begin{array}{c}\text { BNR } \\
\%\end{array}$ & $\begin{array}{c}\text { LDOAR } \\
\%\end{array}$ & $\begin{array}{c}\text { PS1 } \\
\%\end{array}$ & $\begin{array}{c}\text { PS2 } \\
\%\end{array}$ & $\begin{array}{c}\text { BFP } \\
\%\end{array}$ & $\begin{array}{c}\text { BNP } \\
\%\end{array}$ & $\begin{array}{c}\text { LDOAP } \\
\%\end{array}$ \\
\hline CC1 & 66.66 & 83.33 & 83.33 & 83.33 & 83.33 & 83.33 & 33.33 & 83.33 \\
CC2 & 83.33 & 100 & 50.00 & 83.33 & 83.33 & 83.33 & 83.33 & 100 \\
CC3 & 83.33 & 100 & 83.33 & 100 & 33.33 & 66.66 & 50.00 & 66.66 \\
CC4 & 83.33 & 100 & 83.33 & 83.33 & 100 & 83.33 & 100 & 83.33 \\
CC5 & 83.33 & 83.33 & 100 & 83.33 & 66.66 & 83.33 & 100 & 66.66 \\
CC6 & 66.66 & 83.33 & 100 & 66.66 & 83.33 & 66.66 & 83.33 & 66.66 \\
CC7 & 83.33 & 83.33 & 100 & 83.33 & 83.33 & 66.66 & 83.33 & 83.33 \\
CC8 & 100 & 83.33 & 100 & 83.33 & 33.33 & 33.33 & 50.00 & 33.33 \\
CC9 & 83.33 & 83.33 & 100 & 83.33 & 66.66 & 66.66 & 83.33 & 66.66 \\
CC10 & 83.33 & 83.33 & 100 & 100 & 83.33 & 33.33 & .1600 & 33.33 \\
CC11 & 66.66 & 83.33 & 83.33 & 100 & 33.33 & 83.33 & 66.66 & 83.33 \\
CC12 & 83.33 & 83.33 & 100 & 83.33 & 66.66 & 66.66 & 83.33 & 83.33 \\
CC13 & 100 & 100 & 83.33 & 100 & 50.00 & 66.66 & 50.00 & 33.33 \\
CC14 & 83.33 & 83.33 & 66.66 & 83.33 & 83.33 & 83.33 & 66.66 & 66.66 \\
CC15 & 66.66 & 83.33 & 83.33 & 100 & 100 & 100 & 83.33 & 66.66 \\
\hline
\end{tabular}

$\mathrm{BFR}=$ biclausal finite reflexives, BNR = biclausal non-finite reflexives, PS1 = possessive structures $1, \mathrm{PS} 2=$ possessive structures $2, \mathrm{LDOAR}=$ long-distance object antecedent reflexive, $\mathrm{BFP}=$ biclausal finite pronoun, $\mathrm{BNP}=$ biclausal non-finite pronoun, LDOAP = long-distance object antecedent pronoun.

Table B4. Results of Chinese-speaking adults.

\begin{tabular}{|c|c|c|c|c|c|c|c|c|}
\hline Participant & $\begin{array}{c}\text { BFR } \\
\%\end{array}$ & $\begin{array}{c}\text { BNR } \\
\%\end{array}$ & $\begin{array}{c}\text { LDOAR } \\
\%\end{array}$ & $\begin{array}{c}\text { PS1 } \\
\%\end{array}$ & $\begin{array}{c}\text { PS2 } \\
\%\end{array}$ & $\begin{array}{c}\text { BFP } \\
\%\end{array}$ & $\begin{array}{c}\text { BNP } \\
\%\end{array}$ & $\begin{array}{c}\text { LDOAP } \\
\%\end{array}$ \\
\hline CA1 & 83.33 & 83.33 & 16.66 & 66.66 & 33.33 & 83.33 & 100 & 83.33 \\
\hline CA2 & 66.66 & 83.33 & 83.33 & 100 & 66.66 & 83.33 & 66.66 & 83.33 \\
\hline CA3 & 66.66 & 83.33 & 50.00 & 83.33 & 83.33 & 66.66 & 50.00 & 50.00 \\
\hline CA4 & 83.33 & 66.66 & 83.33 & 83.33 & 100 & 83.33 & 83.33 & 100 \\
\hline CA5 & 66.66 & 83.33 & 83.33 & 100 & 66.66 & 83.33 & 83.33 & 66.66 \\
\hline CA6 & 83.33 & 66.66 & 100 & 83.33 & 83.33 & 83.33 & 83.33 & 100 \\
\hline $\mathrm{CA} 7$ & 50.00 & 66.66 & 66.66 & 83.33 & 50.00 & 16.66 & 66.66 & 83.33 \\
\hline CA8 & 66.66 & 83.33 & 100 & 83.33 & 83.33 & 50.00 & 83.33 & 66.66 \\
\hline CA9 & 83.33 & 66.66 & 83.33 & 100 & 83.33 & 83.33 & 83.33 & 100 \\
\hline CA10 & 66.66 & 83.33 & 83.33 & 100 & 66.66 & 83.33 & 66.66 & 83.33 \\
\hline CA11 & 83.33 & 66.66 & 83.33 & 83.33 & 83.33 & 66.66 & 83.33 & 66.66 \\
\hline CA12 & 100 & 100 & 100 & 100 & 100 & 16.66 & 50.00 & 33.33 \\
\hline CA13 & 66.66 & 83.33 & 100 & 83.33 & 66.66 & 66.66 & 83.33 & 83.33 \\
\hline CA14 & 66.66 & 83.33 & 100 & 83.33 & 83.33 & 83.33 & 83.33 & 100 \\
\hline CA15 & 83.33 & 100 & 83.33 & 100 & 50.00 & 66.66 & 50.00 & 83.33 \\
\hline
\end{tabular}

$\mathrm{BFR}=$ biclausal finite reflexives, BNR = biclausal non-finite reflexives, PS1 = possessive structures 1 , PS2 = possessive structures $2, \mathrm{LDOAR}=$ long-distance object antecedent reflexive, $\mathrm{BFP}=$ biclausal finite pronoun, $\mathrm{BNP}=$ biclausal non-finite pronoun, LDOAP = long-distance object antecedent pronoun. 